\title{
The GPI-modified proteins Pga59 and Pga62 of Candida albicans are required for cell wall integrity
}

Correspondence

Christophe d'Enfert denfert@pasteur.fr

Received 4 March 2009

Accepted 8 March 2009

\author{
Emilia Moreno-Ruiz, ${ }^{1}$ Giuseppe Ortu, ${ }^{1,2}+$ Piet W. J. de Groot, ${ }^{3}$ \\ Fabien Cottier, ${ }^{1} \ddagger$ Céline Loussert, ${ }^{4}$ Marie-Christine Prévost, ${ }^{4}$ \\ Chris de Koster, ${ }^{3}$ Frans M. Klis, ${ }^{3}$ Sophie Goyard ${ }^{1} \S$ and Christophe d'Enfert ${ }^{1}$ \\ ${ }^{1}$ Institut Pasteur, Unité Biologie et Pathogénicité Fongiques, INRA USC2019, Paris, France \\ ${ }^{2}$ Sezione di Microbiologia generale ed Applicat, DISAABA, Sassari, Italy \\ ${ }^{3}$ Swammerdam Institute for Life Sciences, University of Amsterdam, Amsterdam, The Netherlands \\ ${ }^{4}$ Plate-forme de Microscopie Ultrastructurale, Institut Pasteur, Paris, France
}

\begin{abstract}
The fungal cell wall is essential in maintaining cellular integrity and plays key roles in the interplay between fungal pathogens and their hosts. The PGA59 and PGA62 genes encode two short and related glycosylphosphatidylinositol-anchored cell wall proteins and their expression has been previously shown to be strongly upregulated when the human pathogen Candida albicans grows as biofilms. Using GFP fusion proteins, we have shown that Pga59 and Pga62 are cell-wall-

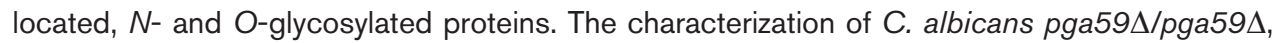
pga62 $\Delta /$ pga62 $\Delta$ and pga59 $/$ pga59 $\Delta$ pga62 $\Delta /$ pga62 $\Delta$ mutants suggested a minor role of these two proteins in hyphal morphogenesis and that they are not critical to biofilm formation.

Importantly, the sensitivity to different cell-wall-perturbing agents was altered in these mutants. In particular, simultaneous inactivation of PGA59 and PGA62 resulted in high sensitivity to Calcofluor white, Congo red and nikkomicin $Z$ and in resistance to caspofungin. Furthermore, cell wall composition and observation by transmission electron microscopy indicated an altered cell wall structure in the mutant strains. Collectively, these data suggest that the cell wall proteins Pga59 and Pga62 contribute to cell wall stability and structure.
\end{abstract}

\section{INTRODUCTION}

The cell wall is an essential component of fungal cells, preserving cellular integrity and playing a central role in the interaction of fungi with their environment. This is particularly the case for pathogenic fungi such as the opportunistic yeast pathogen Candida albicans, where the cell wall has been shown to play central roles in adhesion, virulence, biofilm formation, infection and immunomodulation (Albrecht et al., 2006; Douglas, 2003; Netea et al., 2006; Richard et al., 2002b; Sundstrom, 2002). Because of the essential role of the cell wall in cellular integrity and fungal specificity of some enzymes involved in its biogenesis, it is a recognized target for the development

†Present address: Laboratoire de Génétique Moléculaire des Champignons Phytopathogènes, Institut de Génétique Moléculaire, Université Paris-Sud, Orsay, France.

‡Present address: Department of Biosciences, University of Kent, Canterbury, UK.

§Present address: Laboratoire d'Immunologie des Infections á Trypanosoma, Institut Pasteur, Paris, France.

Abbreviations: CFW, Calcofluor white; CR, Congo red; GPI, glycosylphosphatidylinositol; MM, molecular mass. of novel antifungals (e.g. echinocandins that target the $\beta$ 1,3-glucan synthase) (Latge, 2007).

The organization of the fungal cell wall has been mainly characterized in the yeasts Saccharomyces cerevisiae and C. albicans and in the filamentous fungus Aspergillus fumigatus (Klis et al., 2006; Latge, 2007; Lesage \& Bussey, 2006; Ruiz-Herrera et al., 2006). The yeast cell wall has a bilayered structure. The inner part is composed of a network of $\beta$-1,3-glucan molecules linked by hydrogen bonds. These chains can be bound covalently to $\beta$-1,6-glucan molecules and to chitin chains. The outer part of the cell wall is composed mainly of mannoproteins (Klis et al., 2006, 2001; Lesage \& Bussey, 2006). Most proteins in the cell wall of ascomycetous yeasts are glycosylphosphatidylinositolanchored proteins (GPI-modified proteins) that become covalently linked to $\beta$-1,6-glucan through a remnant of their GPI anchor. As the $\beta$-1,6-glucan moiety can be linked to $\beta$-1,3-glucan or chitin, the cell wall GPI-modified proteins are strongly linked to the cell wall (De Groot et al., 2005; Klis et al., 2001; Richard \& Plaine, 2007).

GPI-modified proteins share a similar structure: an Nterminal sequence for translocation into the endoplasmic 
reticulum, a mature domain, and a C-terminal hydrophobic region for anchorage to the endoplasmic reticulum membrane. Nine or ten amino acids before this C-terminal sequence the so-called $\omega$ site is localized, where the protein is cleaved prior to its ligation to a pre-assembled GPI anchor (Thomas et al., 1990). The core GPI anchor is formed of a lipid group (the membrane anchor), a myoinositol residue, a glucosamine residue, three mannose residues and a phosphoethanolamine group that connects the GPI anchor to the protein via an amide linkage (Tiede et al., 1999). Cell wall GPI-modified proteins are transiently localized in the plasma membrane, the mature domain facing the external milieu. Subsequently, they are removed from the membrane by a cleavage step, which takes place between the glucosamine residue and the first mannose residue of the GPI anchor, and covalently bound to $\beta$-1,6-glucan (Kapteyn et al., 1996; Kollar et al., 1997; van der Vaart et al., 1996). Plasma membrane or cell wall localization of GPI-modified proteins can be predicted in S. cerevisiae, where dibasic residues (arginine and lysine for instance) upstream of the $\omega$ site determine plasma membrane localization of the GPI-modified protein (Caro et al., 1997; Frieman \& Cormack, 2003). Cell wall localization of GPI-modified proteins is determined by the absence of this dibasic motif and by the presence of hydrophobic residues in positions $\omega-2, \omega-4$ or $\omega-5$ (Caro et al., 1997; Frieman \& Cormack, 2003; Hamada et al., 1999). Furthermore, it seems that the sequence of the protein attached to the GPI anchor might be involved in defining the GPI-modified protein localization. In particular, long regions rich in serine and threonine residues in the $\mathrm{C}$ terminal part of mature GPI-modified proteins seem to promote cell wall localization (Frieman \& Cormack, 2004). In the case of $C$. albicans, localization of GPI-modified proteins appears to be dependent on similar as well as additional determinants (Richard \& Plaine, 2007). For instance, Mao et al. (2008) have shown that the occurrence of an aromatic residue and an acidic residue in positions $\omega-2$ and $\omega-1$, respectively, promotes cell wall localization of C. albicans GPI-modified proteins. There are 115 putative GPI-modified proteins in C. albicans and most of them have unknown functions. However, several have been implicated in processes such as cell wall biogenesis and remodelling, oxidant adaptation and adherence, or have specific enzymic functions (reviewed by Richard \& Plaine, 2007).

In a previous study we have shown that the C. albicans PGA59 and PGA62 genes, encoding two related cell wall GPI-modified proteins, are expressed to much higher levels in biofilms than in planktonic cultures (Garcia-Sanchez et al., 2004). The ability of C. albicans to form biofilms three-dimensional microbial communities attached to a surface and embedded in an extracellular matrix - plays important roles in the virulence of this fungus and in the management of $C$. albicans infections, since biofilm cells show decreased susceptibility to most antifungals. $C$. albicans biofilms are composed of yeast and hyphal cells, and the ability to make the transition from the yeast form to the hyphal form is crucial for efficient biofilm formation (Ramage et al., 2002; Richard et al., 2005) in addition to being a critical determinant of C. albicans virulence (Saville et al., 2003). Here, we have used C. albicans deletion mutants in order to evaluate the role of PGA59 and PGA62 in biofilm formation. Our results show that Pga59 and Pga62 are cell wall GPI-modified proteins involved in the maintenance of cell wall integrity and to some extent in hyphal morphogenesis but that these proteins are dispensable for biofilm formation.

\section{METHODS}

Strains, media, and growth conditions. All C. albicans strains used in this study are listed in Table 1 . Strains were routinely grown at $30{ }^{\circ} \mathrm{C}$ on YPD medium ( $1 \%$ yeast extract, $2 \%$ peptone, $2 \%$ glucose), or SD minimal medium $(0.67 \%$ yeast nitrogen base without amino acids, $0.4 \%$ or $2 \%$ glucose $)$ supplemented with uridine $\left(40 \mu \mathrm{g} \mathrm{ml}^{-1}\right)$, arginine $\left(20 \mu \mathrm{g} \mathrm{ml}^{-1}\right)$ and histidine $\left(20 \mu \mathrm{g} \mathrm{ml}^{-1}\right)$. Lee's (Lee et al., 1975) or RPMI 1640 (Gibco) medium was used to induce hyphal formation in liquid culture. RPMI 1640 medium was buffered with $50 \mathrm{mM}$ HEPES/NaOH, pH 7.3. A $40 \mathrm{~h}$ saturated culture in YPD or a $48 \mathrm{~h}$ saturated culture in SD $2 \%$ glucose was diluted to an $\mathrm{OD}_{600}$ of $0.2-0.5$ in the corresponding medium and incubated at $37{ }^{\circ} \mathrm{C}$ for $4-$ $5 \mathrm{~h}$ with shaking. When hyphal formation in embedded conditions was studied, 50-100 c.f.u. were mixed with $10 \mathrm{ml}$ YPS medium ( $1 \%$ yeast extract, $2 \%$ peptone, $2 \%$ sucrose, $1 \%$ agar) at $55{ }^{\circ} \mathrm{C}$, plated on a layer of YPS and subsequently overlaid with a second layer of YPS. Plates were incubated at $25^{\circ} \mathrm{C}$ for 7-10 days. C. albicans was routinely transformed by the lithium acetate-PEG protocol (Walther \& Wendland, 2003). When nourseothricine was used as resistance marker, after overnight incubation at $30{ }^{\circ} \mathrm{C}$ in $\mathrm{PEG}$, transformants were plated in YPD and replica plated in YPD $+50 / 100 / 150 \mu \mathrm{g}$ nourseothricine $\mu \mathrm{l}^{-1}$ (Werner Bioagent) after $24 \mathrm{~h}$ at $30^{\circ} \mathrm{C}$. Transformants were obtained after $48 \mathrm{~h}$ incubation at $30{ }^{\circ} \mathrm{C}$.

Growth assays. Growth curves were performed in 96-well plates in a Tecan Infinite M200 microplate reader. Relative fitness $(W)$ of a strain was calculated as the ratio of the doubling time of the wild-type strain $\left(D_{\mathrm{wt}}\right)$ to the doubling time of the strain of interest $\left(D_{\mathrm{x}}\right)\left(W=D_{\mathrm{wt}} / D_{\mathrm{x}}\right)$, which is equivalent to the ratio of the relative growth rate of the strain of interest and of the wild-type strain (St Onge et al., 2007). Means and standard deviations are presented for fitness values determined in at least two biological replicates, each including at least four technical replicates, with standard deviations not exceeding $5 \%$ of the doubling times obtained for a given strain.

Biofilm formation assays. Biofilms were produced in microfermenters and quantified as described previously (Garcia-Sanchez et al., 2004; Goyard et al., 2008). Alternatively, biofilms were produced in microtitre plates as follows. Saturated cultures in SD $2 \%$ glucose were diluted to $\mathrm{OD}_{600} 0.05$ in $100 \mu \mathrm{l}$ RPMI 1640 medium in 96-well microtitre plates and incubated at $37{ }^{\circ} \mathrm{C}$ for $24 \mathrm{~h}$. The microtitre plates were then washed with PBS using a HydroFlex platform (Tecan) and $100 \mu$ l of a $1 \times$ FDA solution $(50 \times$ stock: fluorescein diacetate, $2 \mathrm{~g}^{-1}$ in acetone; diluted to $1 \times$ in PBS) was added per well (Honraet et al., 2005). Plates were wrapped in aluminium foil and incubated for $1 \mathrm{~h}$ at $37{ }^{\circ} \mathrm{C}$ before measuring fluorescence in a Tecan Infinite M200 microplate reader using an excitation filter of $486 \pm 9 \mathrm{~nm}$ and an emission filter of $535 \pm 20 \mathrm{~nm}$.

Plasmid and strain constructions. All oligonucleotides used in this study are listed in Table 2. 
Table 1. Strains used in this study

\begin{tabular}{|c|c|c|c|}
\hline Strain & Parent & Genotype & Reference \\
\hline SC5314 & & Wild-type strain & Gillum et al. (1984) \\
\hline CAF2 & & URA3/ura3: : $\lambda$ imm434 & Fonzi \& Irwin (1993) \\
\hline HLC54 & & 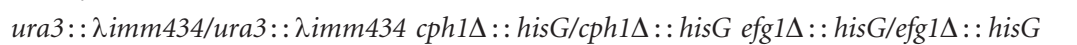 & Lo et al. (1997) \\
\hline BWP17 & & 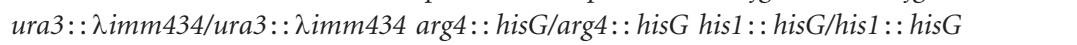 & Wilson et al. (1999) \\
\hline BWP17U & BWP17 & ura3:: גimm434/URA3 arg4:: hisG/arg4:: hisG his1:: hisG/ his1:: hisG & Goyard \\
\hline BWP17AHU & BWP17U & ura3::入imm434/URA3 arg4:: hisG/ARG4 his1:: hisG/HIS1 & Firon et al. (2007) \\
\hline CEC56 & BWP17 & 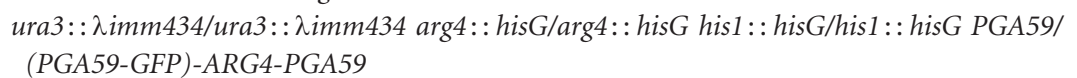 & This work \\
\hline CEC65 & BWP17 & 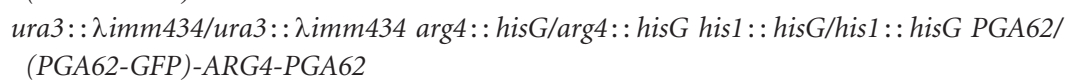 & This work \\
\hline CEC373 & BWP17U & 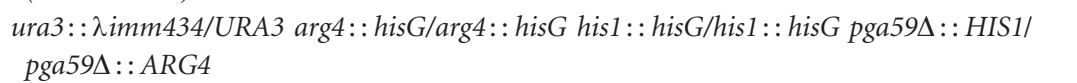 & This work \\
\hline CEC374 & BWP17U & 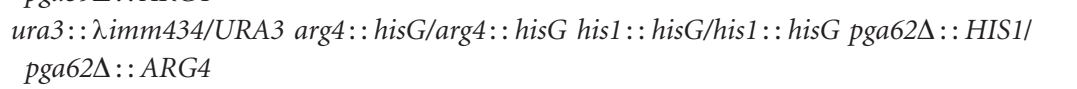 & This work \\
\hline CEC377 & BWP17 & 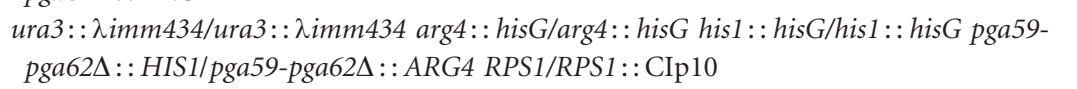 & This work \\
\hline CEC832 & CEC373 & 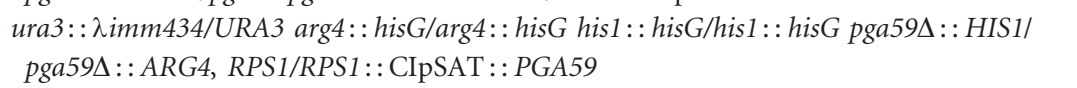 & This work \\
\hline CEC837 & CEC374 & 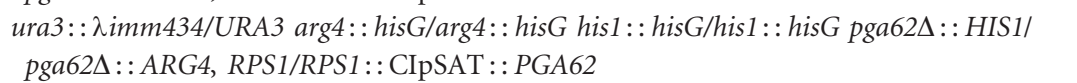 & This work \\
\hline CEC922 & BWP17 & 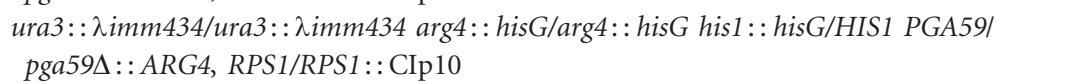 & This work \\
\hline CEC992 & BWP17 & 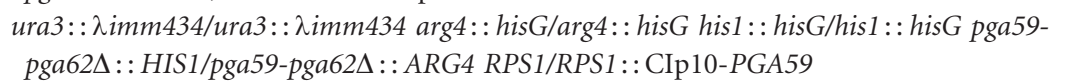 & This work \\
\hline CEC995 & BWP17 & 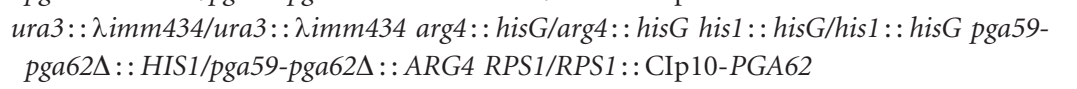 & This work \\
\hline CEC997 & BWP17 & 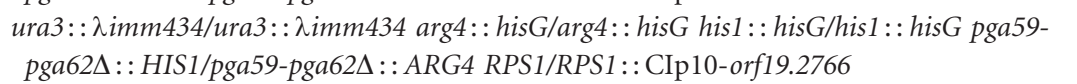 & This work \\
\hline
\end{tabular}

To study the localization of Pga59 and Pga62, plasmids carrying PGA59-GFP and PGA62-GFP fusions were constructed. Regions including the PGA59 or PGA62 ORFs flanked by $1 \mathrm{~kb}$ of the corresponding upstream genomic region and $500 \mathrm{bp}$ or $700 \mathrm{bp}$ of the corresponding downstream genomic region were amplified using oligonucleotides PGA59.01 and PGA59.02 or PGA62.05 and PGA62.06, respectively. Amplification products were cloned in pGEM-T, yielding pGEM-T : : PGA59 and pGEM-T : : PGA62, respectively. The green fluorescent protein (GFP) coding sequence (without stop codon) was amplified from plasmid pMG1602 (Gerami-Nejad et al., 2001) using primers YGFP.01 and YGFP.02. The resulting PCR product was subcloned at $B a m \mathrm{HI}$ and $B s r \mathrm{GI}$ sites into pGEMT::PGA59 or pGEM-T::PGA62 that had been amplified using primers PGA59Y.01 and PGA59Y.02 or PGA62Y.01 and PGA62Y.02, respectively. This resulted in plasmids pGEM-T:: (PGA59-GFP) and pGEM-T : : $(P G A 62-G F P)$, where the GFP coding sequence is inserted in-frame between the codons for the second and third amino acids of the mature Pga59 or Pga62 proteins, as predicted by SignalP (http:// www.cbs.dtu.dk/services/SignalP/). The C. albicans ARG4 gene, amplified from plasmid pDDB166 (Enloe et al., 2000) using oligonucleotides ARG4.01 and ARG4.02, was cloned between NotI and SacI sites in these plasmids, yielding pGEM-T:: (PGA59-GFP, $A R G 4)$ and pGEM-T::(PGA62-GFP, ARG4), respectively. All plasmids were sequenced to verify appropriate amplification of the ORFs. Strains CEC56 and CEC65 were obtained via transformation of strain BWP17 (Table 1) with SnaBI- or BstBI-linearized pGEMT::(PGA59-GFP, ARG4) or pGEM-T::(PGA62-GFP, ARG4), respectively. Integration of the PGA59-GFP or PGA62-GFP fusion at the PGA59 or PGA62 loci, respectively, was confirmed by PCR analysis and Southern hybridization. Cells were observed with an ApoTome microscope (Carl Zeiss) or an Eclipse E600 microscope equipped with a Nikon DXM1200F digital camera.

Knockout mutants were constructed in BWP17 or BWP17U by sequential replacement of the complete ORF of both alleles of each gene by PCR-generated HIS1 or ARG4 disruption cassettes flanked by $100 \mathrm{bp}$ of target homology region through sequential transformation, as described elsewhere (Gola et al., 2003). Oligonucleotides 5-PGA59 and 3-PGA59 were used for the construction of strain CEC373 (pga594/pga594) in BWP17U (Table 1). Oligonucleotides 5-PGA62 and 3-PGA62 were used for the construction of strain CEC374

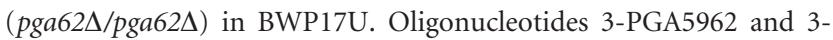
PGA59 were used for the construction of strain CEC377 (pga594-

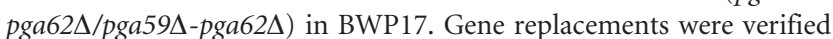
by PCR. Southern analyses were also performed using either a PGA59 or PGA62 fragment or an ARG4 or HIS1 fragment as probes on EcoRI-digested genomic DNA. Prior to phenotypic analysis, strain CEC377 was transformed to uracil prototrophy using the StuIlinearized CIp10 plasmid, which carries the URA3 gene and integrates at the RPS1 locus (Murad et al., 2000).

For reintroduction of the wild-type PGA59 or PGA62 alleles in C.

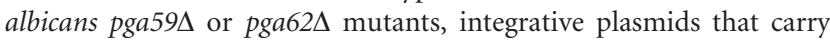
the corresponding genomic regions were constructed. Regions including the PGA59 or PGA62 ORFs flanked by $1 \mathrm{~kb}$ of the corresponding upstream and downstream genomic region were amplified using oligonucleotides RegPga59-start and RegPga59-end or RegPga62-start and RegPga62-end, respectively. Amplification products were then cloned in the KpnI and SalI sites of plasmid 
Table 2. Oligonucleotides used in this study.

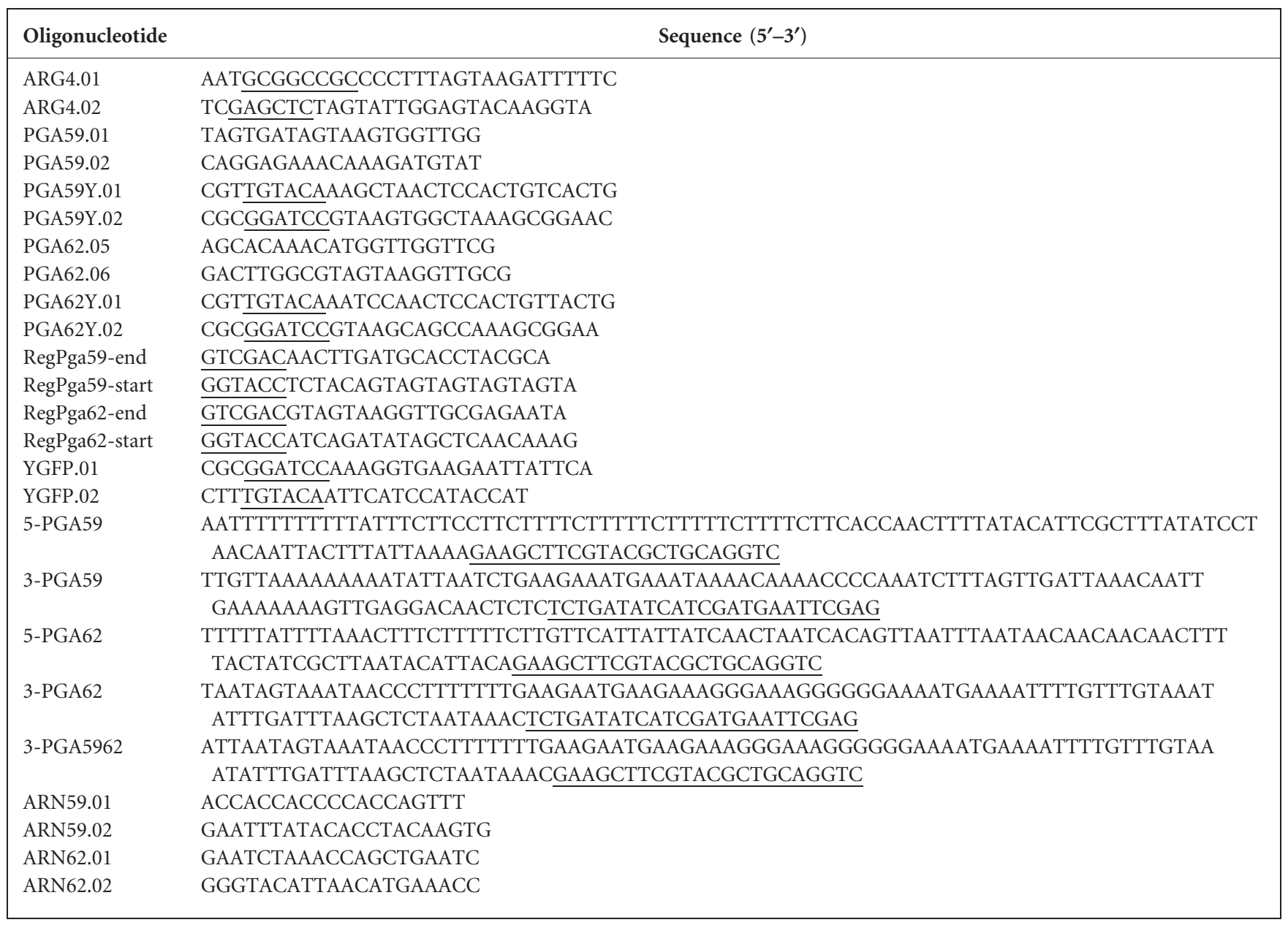

CIPSAT1 or CIpSAT2, yielding plasmids CIPSAT1:: PGA59 and CIPSAT2:: PGA62, respectively. CIpSAT1 and CIpSAT2 are derivatives of CIp10 (Murad et al., 2000) where the URA3 gene has been respectively substituted by the caSAT1 (Reuss et al., 2004) or CaNAT1 (Shen et al., 2005) markers that confer resistance to nourseothricine (Reuss et al., 2004).

RNA preparation and Northern blotting. Total RNA preparation and Northern blot hybridizations were carried out as previously described (Garcia-Sanchez et al., 2004). Probes for the PGA59 and PGA62 mRNAs were amplified from C. albicans genomic DNA using oligonucleotides ARN59.01 and ARN59.02 and ARN62.01 and ARN62.02, respectively, and labelled with $\left[\alpha_{-}{ }^{32} \mathrm{P}\right] \mathrm{dCTP}$ using the Rediprime II DNA labelling system (GE Healthcare). The probes matched the 3'UTR of PGA59 and PGA62, respectively, in order to avoid potential cross-hybridizations to the PGA62 and PGA59 mRNAs, respectively.

Cell wall isolation and composition analysis. Cell wall isolation was performed as described previously (De Groot et al., 2004). Briefly, cells from an overnight culture $\left(\mathrm{OD}_{600} 4\right)$ in $\mathrm{SD}$ at $30{ }^{\circ} \mathrm{C}$ were harvested and washed with $10 \mathrm{mM}$ Tris/ $\mathrm{HCl} \mathrm{pH} \mathrm{7.5.} \mathrm{Cells} \mathrm{in} 10 \mathrm{mM}$ Tris/ $\mathrm{HCl} \mathrm{pH} 7.5$ were disintegrated with $0.25-0.50 \mathrm{~mm}$ glass beads (Emergo) in the presence of a protease inhibitor cocktail (Sigma) using a Bio-Savant Fast Prep 120 instrument (Qbiogene). Cell walls were washed extensively with $1 \mathrm{M} \mathrm{NaCl}$ and extracted twice with $2 \%$ (w/v) SDS, $100 \mathrm{mM}$ NaEDTA, $100 \mathrm{mM} \beta$-mercaptoethanol, $50 \mathrm{mM}$
Tris/ $\mathrm{HCl} \mathrm{pH} 7.8$ for $5 \mathrm{~min}$ at $100{ }^{\circ} \mathrm{C}$ to remove non-covalentlylinked proteins. SDS-extracted walls were extensively washed with water and freeze-dried.

For quantification of total cell wall glucan and mannan, isolated cell walls were hydrolysed to mannose and glucose using the sulfuric acid hydrolysis method (Dallies et al., 1998). Briefly, about $4 \mathrm{mg}$ freezedried walls were incubated in $100 \mu \mathrm{l} 72 \%(\mathrm{v} / \mathrm{v}) \mathrm{H}_{2} \mathrm{SO}_{4}$ for $3 \mathrm{~h}$ at room temperature. Then, samples were diluted with $575 \mu$ l distilled $\mathrm{H}_{2} \mathrm{O}$ to obtain a $2 \mathrm{M} \mathrm{H}_{2} \mathrm{SO}_{4}$ solution and incubated for $4 \mathrm{~h}$ at $100{ }^{\circ} \mathrm{C}$. Amounts of mannose and glucose in the samples were determined by HPLC (LKB) on a REZEX organic acid analysis column (Phenomenex) at $40{ }^{\circ} \mathrm{C}$ with $7.2 \mathrm{mM} \mathrm{H}_{2} \mathrm{SO}_{4}$ as eluent using an $\mathrm{RI}$ 1530 refractive index detector (Jasco) and AZUR chromatography software for data integration.

Cell wall protein content was quantified as described by Kapteyn et al. (2001). About $4 \mathrm{mg}$ freeze-dried walls were resuspended in $100 \mu \mathrm{l}$ $1 \mathrm{M} \mathrm{NaOH}$ and incubated at $100{ }^{\circ} \mathrm{C}$ for $10 \mathrm{~min}$. The suspension was then neutralized by addition of $100 \mu \mathrm{l} 1 \mathrm{M} \mathrm{HCl}$ and centrifuged. The protein concentration of the supernatant was determined with the BCA protein assay reagent (Pierce) using BSA as a reference.

For chitin quantification pellets of the neutralized alkaline extracts (see above) were used. They were washed once with $1 \mathrm{ml} \mathrm{H}_{2} \mathrm{O}$ and then hydrolysed by incubating in $6 \mathrm{M} \mathrm{HCl}$ at $100{ }^{\circ} \mathrm{C}$ for $17 \mathrm{~h}$, after which the samples were air-dried at $65{ }^{\circ} \mathrm{C}$ and resuspended in $1 \mathrm{ml}$ $\mathrm{H}_{2} \mathrm{O}$. After centrifugation, $100 \mu \mathrm{l}$ of the supernatant was mixed with 
$100 \mu \mathrm{l} 4 \%(\mathrm{w} / \mathrm{v})$ acetylacetone in $0.75 \mathrm{M} \mathrm{Na}_{2} \mathrm{CO}_{3}$, and the mixture was incubated at $100{ }^{\circ} \mathrm{C}$ for $20 \mathrm{~min}$. Subsequently, $0.7 \mathrm{ml} 96 \%$ ethanol and $100 \mu \mathrm{l} 2.7 \%$ (w/v) p-dimethylaminobenzaldehyde in $50 \%(\mathrm{v} / \mathrm{v}) \mathrm{HCl} /$ ethanol were added, and after $1 \mathrm{~h}$ incubation at room temperature, glucosamine content was measured as absorbance at $520 \mathrm{~nm}$. Different concentrations of glucosamine treated in the same way were used as standards (Kapteyn et al., 2001).

Plasma membrane isolation. Plasma membranes were isolated as described elsewhere (Niimi et al., 2004). Briefly, overnight cultures in YPD at $30{ }^{\circ} \mathrm{C}$ were harvested and pellets were concentrated 20 times and washed with cold $\mathrm{H}_{2} \mathrm{O}$. Cells were then resuspended on ice in $50 \mathrm{mM}$ Tris ( $\mathrm{pH}$ 7.5), $2 \mathrm{mM}$ EDTA, and $1 \mathrm{mM}$ phenylmethylsulfonyl fluoride, and disrupted with $0.25-0.50 \mathrm{~mm}$ glass beads (Emergo) in the presence of a protease inhibitor cocktail (Sigma) using a BioSavant Fast Prep 120 (Qbiogene). Centrifugation for $10 \mathrm{~min}$ at $2000 \mathrm{~g}$ removed cell debris and unbroken cells. Centrifugation for $45 \mathrm{~min}$ at $30000 \mathrm{~g}$ yielded a crude membrane fraction from the cell-free supernatant. The plasma membrane fraction was enriched by selective precipitation of mitochondria at $\mathrm{pH} 5.1$ as described previously (Goffeau \& Dufour, 1988), pelleted by centrifugation for $45 \mathrm{~min}$ at $30000 \mathrm{~g}$, resuspended in $10 \mathrm{mM}$ Tris $(\mathrm{pH} 7.0) / 0.5 \mathrm{mM}$ EDTA/20\% (v/v) glycerol, and stored at $-80{ }^{\circ} \mathrm{C}$.

Immunodetection of Pga59-GFP and Pga62-GFP. Immunoblots were performed with equivalent amounts from the different cell fractions, referring all to $4 \mathrm{mg}$ dry weight of cell walls. Cell wall fractions were digested with endo- $\beta$-1,6-glucanase (ProZyme) (Kapteyn et al., 2001) prior to loading. Proteins were separated using 3-15\% gradient SDS-PAGE, and transferred to a nitrocellulose membrane. Anti-GFP antiserum (Molecular Probes) was used at $1: 2000$ dilution to detect Pga59-GFP and Pga62-GFP.

MS identification of Pga59-GFP and Pga62-GFP and other cell wall proteins. Cell walls were treated with DTT, $S$-alkylated with iodoacetamide and digested overnight with sequencing-grade trypsin (Roche Molecular Biochemicals) as described by Yin et al. (2005). Solubilized peptides were desalted and collected on OMIX $\mu \mathrm{C}_{18}$ pipette tips (Varian), washed with $0.1 \%$ formic acid, and eluted with $60 \%$ acetonitrile $/ 0.1 \%$ formic acid. For MALDI analysis, the eluates were mixed $1: 1(\mathrm{v} / \mathrm{v})$ with a solution containing $10 \mathrm{mg} \alpha$-cyano-4hydroxycinnamic acid $\mathrm{ml}^{-1}$ (Sigma-Aldrich) in $50 \%$ ethanol $/ 50 \%$ acetonitrile $/ 0.3 \%$ trifluoroacetic acid. The mixture was spotted on a target plate and allowed to dry at room temperature. Reflectron MALDI-TOF spectra were acquired on a TofSpec 2E (Waters) and analysed using Masslynx software (Waters) for the presence of GFPderived peptides.

For MS/MS information, proteolytic digests derived from $30 \mu \mathrm{g}$ freezedried cell walls were fractionated on a $150 \mathrm{~mm} \times 75 \mu \mathrm{m}$ (length $\times$ inner diameter) reversed-phase capillary column (PepMap C18, Dionex) using an Ultimate nano-LC system (Dionex). The peptides were separated over $30 \mathrm{~min}$ with a two-step linear gradient of $0-50 \%$ acetonitrile $+0.1 \%$ formic acid and the flow of $300 \mathrm{nl} \mathrm{min}^{-1}$ was directly electrosprayed into the Q-TOF1 (Waters) operating in datadependent MS and MS/MS mode. The Masslynx software (Waters) was instructed to select ions ranging from $\mathrm{m} / z 350$ to 1500 with a charge state of at least $2+$ above a BPI ion count threshold of 40 for collisioninduced fragmentation using argon as collision gas. The resulting MS/ MS spectra were processed with the Biolynx tool of the Masslynx software, which generated a peak list (.pkl file) with all precursor and product ions calculated to the corresponding $\mathrm{MH}^{+}$charge state. The peak lists (.pkl file) generated with the Masslynx software were submitted to MASCOT (version 2.05, Matrix Science) using the MSDB protein database and an in-house-prepared C. albicans database and search parameters as described with $P<0.05$ for random occurrence of each peptide match (Sosinska et al., 2008).
Freeze-substitution transmission electron microscopy. Overnight cultures at $30{ }^{\circ} \mathrm{C}$ in $\mathrm{SD}+\mathrm{Arg}+\mathrm{His}+\mathrm{Uri}$ were concentrated by centrifugation and the pellets were transferred to planchettes of $100 \mu \mathrm{m}$ depth. The samples were immediately cryoimmobilized with an HPM 010 high-pressure freezer (Bal-tec) and stored in liquid nitrogen. Freeze-substitution of the samples was carried out in an AFS (Leica) in acetone containing $1 \%$ osmium tetroxide (Merck). Substitution was carried out for $24 \mathrm{~h}$ at $-90{ }^{\circ} \mathrm{C}$; then the samples were warmed $\left(5{ }^{\circ} \mathrm{C} \mathrm{h}^{-1}\right)$ to $-30{ }^{\circ} \mathrm{C}(3 \mathrm{~h})$ and finally to $0{ }^{\circ} \mathrm{C}$ before removal of the substitution medium and embedding in EPON. Contrasted ultrathin sections $(60 \mathrm{~nm})$ were observed in a JEM 1010 TEM (JEOL).

\section{RESULTS}

\section{PGA59 and PGA62 encode related putative GPI- modified proteins}

Genomic transcript profiling has shown that PGA59 and PGA62 are overexpressed by 3.7- and 2.4-fold in C. albicans biofilm cells relative to planktonic cells (Garcia-Sanchez et al., 2004). As shown in Fig. 1(A), PGA59 (orf19.2767) and PGA62 (orf19.2765) are located in the same region of $C$. albicans strain SC5314 chromosome 4 and transcribed divergently. The $9170 \mathrm{bp}$ region that separates the start codons of PGA59 and PGA62 contains a single $309 \mathrm{bp}$ putative ORF, orf19.2766, that shows poor coding probability according to a GenMark analysis (Braun et al., 2005; d'Enfert et al., 2005), and is absent from the genome of $C$. albicans strain WO-1 as well as other Candida species such as C. lusitaniae, C. tropicalis and C. guillermondii (http:// www.broad.mit.edu/annotation/genome/candida_albicans/ MultiHome.html; Rossignol et al., 2008). Consistently, no expression of orf19.2766 was detected by quantitative RTPCR analysis in YPD or Lee's medium, while PGA59 and PGA62 were expressed in these conditions (data not shown).

Comparison of the deduced amino acid sequences of PGA59 and PGA62 showed that the 113 aa Pga59 and 213 aa Pga62 proteins share three highly similar domains: a signal peptide ( $89 \%$ identity, $100 \%$ similarity), a 42 aa amino-terminal domain (93\% identity, $95 \%$ similarity) and a carboxy-terminal domain typical of GPI-modified proteins $(77 \%$ identity and similarity; Fig. 1B, C). The amino acids upstream of the $\omega$ sites were also conserved, and the absence of a dibasic motif and occurrence of an acidic residue suggested a cell wall location for both Pga59 and Pga62 (Caro et al., 1997; Mao et al., 2008). Pga62 differed from Pga59 by the occurrence of an additional 42 aa repeat (Fig. 1B, C) and of four 10 aa repeats (Fig. 1B, D). The 42 aa repeat was shared by other C. albicans cell wall GPI-modified proteins, including the Cht2 chitinase (Dunkler et al., 2005; McCreath et al., 1995), Hwp1 (Staab \& Sundstrom, 1998; Sundstrom, 2002), Hwp2 (Sohn et al., 2003), Rbt1 (Braun et al., 2000), Eap1 (Li \& Palecek, 2003, 2008), Ywp1 (Granger et al., 2005; Sohn et al., 2003), and three putative GPI-modified proteins, Pga6, Pga18 and Pga38. In these proteins the amino acid repeat was $42-46$ aa 

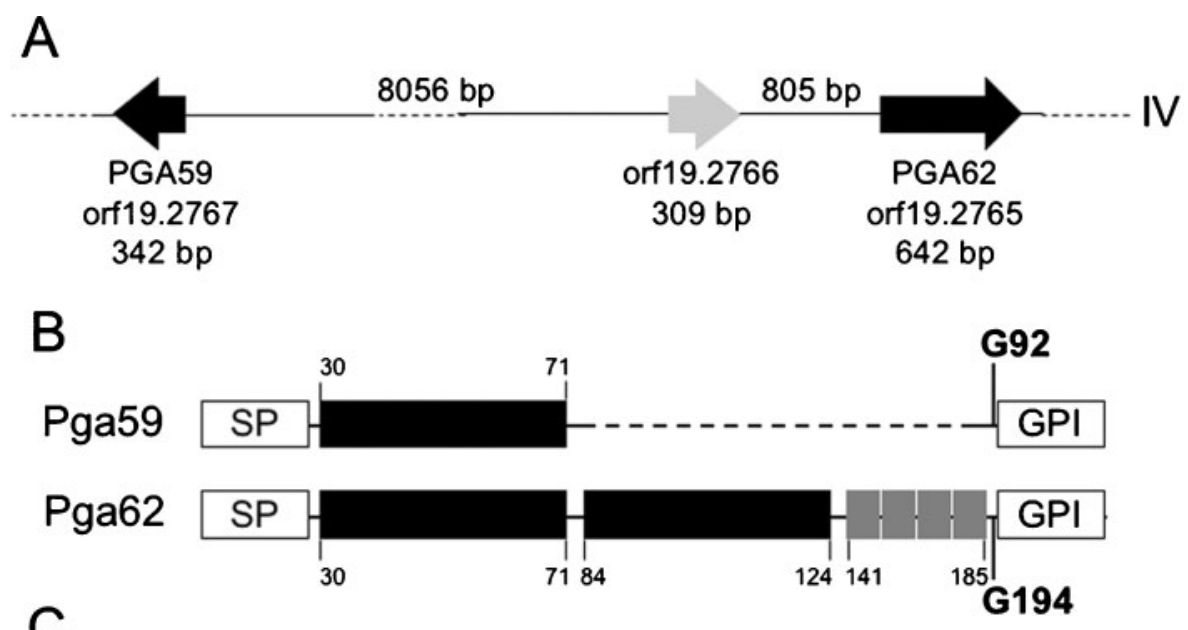

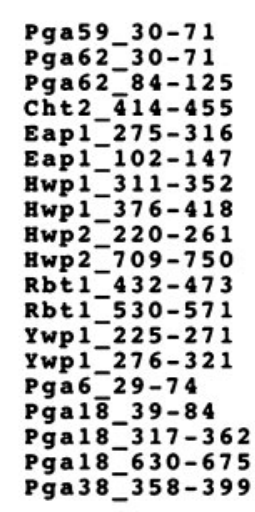

D

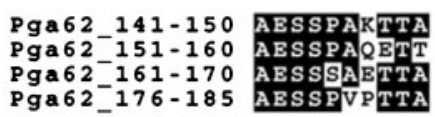

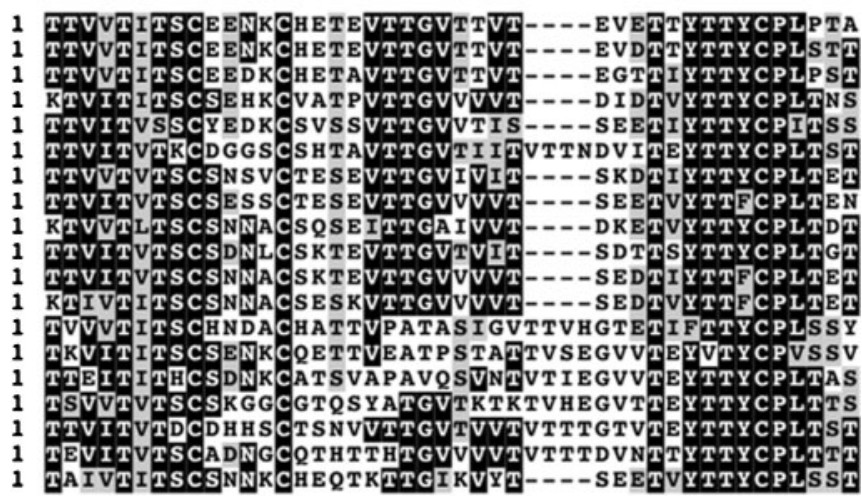

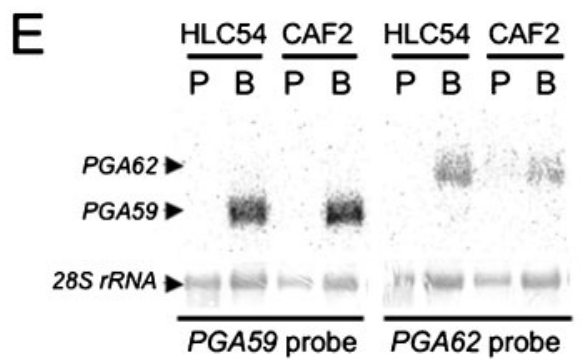

Fig. 1. The C. albicans $P G A 59$ and PGA62 genes encode putative GPI-modified proteins with conserved motifs. (A) Schematic representation of the region of $C$. albicans chromosome 4 harbouring the PGA59 (orf19.2767) and PGA62 (orf19.2765) genes. Both genes are shown as black arrows while the putative ORF lying in the PGA59-PGA62 intergenic region is shown as a grey arrow. (B) Schematic representation of the Pga59 and Pga62 proteins. The N-terminal signal peptide (SP) and the GPI addition signal (GPI) downstream of the predicted $\omega$ sites (Gly92 in Pga59 and Gly194 in Pga62) for GPI anchoring are shown as white boxes. The 42 aa repeats shared by Pga59 and Pga62 are shown as black boxes. The 10 aa repeats specific to Pga62 are shown as grey boxes. Amino acid positions are shown. (C) Multiple alignment of the 42-46 aa repeats identified in Pga59, Pga62 and other C. albicans proteins. The location of the repeats in the different proteins is shown. Identical amino acids shared by $>50 \%$ of the repeats have a black background while similar amino acids shared by $>50 \%$ of the repeats have a grey background. (D) Multiple alignment of the 10 aa repeats identified in Pga62. Amino acids identified in $>75 \%$ of the repeats have a black background. (E) Northern blot analysis of the PGA59 and PGA62 mRNAs in C. albicans strains growing planktonically or as biofilms. Samples $(10 \mu \mathrm{g})$ of total RNA were blotted onto nylon membranes and hybridized to ${ }^{32}$ P-labelled probes for the PGA59 and PGA62 genes. A control row showing the methylene-blue staining of the $28 S$ rRNA

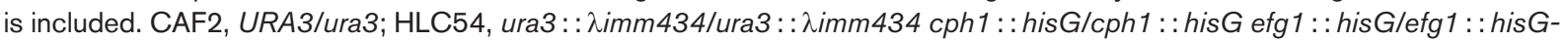
URA3-hisG; P, Planktonic culture ; B, $41 \mathrm{~h}$ biofilm obtained in microfermenters. 
long (Fig. 1C). The 42 aa repeat was also found in other $C$. albicans proteins, such as Iff11 (Bates et al., 2007) and orf19.3621, that are not GPI-modified proteins. Orthologues of PGA62 could be identified in other species of the CTG clade, including C. tropicalis (CTRG_00154), C. guillermondii (CGUG_04576), Debaryomyces hansenii (DEHA0G18986 g, Dujon et al., 2004), Loderomyces elongisporus (LELG_04464) and Pichia stipitis (PICST_66502, Jeffries et al., 2007). In contrast, no orthologue of PGA59 could be identified in these and other species. Proteins orthologous to Pga62 all shared two amino-terminal 42 aa repeats followed by smaller repeats that were not conserved between species.

Because PGA59 and PGA62 are highly related, transcript profiling data indicating the overexpression of both genes in biofilm cells might have resulted from cross-hybridization of the corresponding probes on macro- or microarrays (Garcia-Sanchez et al., 2004). Thus, expression of PGA59 and PGA62 was tested by Northern hybridization of RNA samples prepared from planktonic and biofilm cells. As shown in Fig. 1(E), both PGA59 and PGA62 were highly expressed in biofilm cells relative to planktonic cells and this was independent of the presence of functional EFG1 and $\mathrm{CPH} 1$ genes encoding two transcription factors controlling the yeast-to-hypha switch (Liu et al., 1994; Stoldt et al., 1997), consistent with the transcript profiling data of Garcia-Sanchez et al. (2004). Although data in Fig. 1 (E) suggested that PGA59 and PGA62 are expressed below detectable levels in planktonic cells grown in minimal medium, results published by others and qRT-PCR analysis of RNAs obtained from C. albicans cells grown in YPD or Lee's medium indicated that these genes are expressed under different conditions of planktonic growth (Cantero et al., 2007; Castillo et al., 2006; Copping et al., 2005; Garcia-Sanchez et al., 2005; Harcus et al., 2004; Lan et al., 2004; Sohn et al., 2003; and data not shown).

\section{Pga59 and Pga62 are cell wall proteins}

As in C. albicans predictions about the localization of GPImodified proteins based on the amino acid environment upstream of the $\omega$ site do not always match the experimental data (Richard \& Plaine, 2007), we decided to experimentally localize Pga59 and Pga62. For this purpose, plasmids carrying PGA59-GFP and PGA62-GFP gene fusions were constructed by cloning the GFP coding region immediately downstream of the codons corresponding to the second amino acid in the mature Pga59 or Pga62 protein, respectively (Fig. 2A). Because the cloned GFP region lacked a stop codon, the resulting Pga59-GFP and Pga62-GFP fusion proteins included the signal peptide, GFP, mature domain and GPI-anchor signal peptide of Pga59 or Pga62, respectively (Fig. 2A). Targeting of the PGA59-GFP and PGA62-GFP fusions at the PGA59 and $P G A 62$ loci, respectively, resulted in C. albicans strains CEC56 and CEC65. In these two strains, GFP showed cell surface localization as shown in Fig. 2(B). Cell surface localization was independent of whether cells grew as yeasts or hyphae or in planktonic cultures or biofilms (Fig. 2C and data not shown). However, upon hyphal growth, the Pga59-GFP protein appeared evenly distributed in the cell wall while the Pga62-GFP protein appeared concentrated in the basal cells of hyphae (Fig. 2C).

Confocal microscopy of C. albicans strains CEC56 and CEC65 could not distinguish between localization at the cytoplasmic membrane or association with the cell wall of the Pga59-GFP or Pga62-GFP proteins. Thus, subcellular fractionation of strains CEC56 and CEC65 was achieved and the presence of the fusion proteins in the cell wall, plasma membrane and intracellular fractions was investigated by immunodetection with anti-GFP antibodies. In both cases, two immunoreactive proteins were detected in the protein fraction released by $\beta$-1,6-glucanase from isolated cell walls, one with a molecular mass (MM) above $200 \mathrm{kDa}$ and diffuse migration and one with the MM of GFP and discrete migration (Fig. 3A). The latter protein was likely to represent a degradation product of the Pga59GFP or Pga62-GFP fusion proteins. High MM and diffuse migration are landmarks of highly glycosylated proteins. Pga59 has two putative $N$-glycosylation sites while Pga62 has only one. GFP does not have any $\mathrm{N}$-glycosylation site. Moreover, the mature Pga59 and Pga62 are Ser/Thr-rich proteins (Pga59, 39.2\%; Pga62, 37.5\%) likely to be modified by $\mathrm{O}$-glycosylation. As shown in Fig. 3(B), treatment of the cell-wall-released protein fractions of strains CEC56 and CEC65 with endoglycosidase $\mathrm{H}$ (EndoH) converted the GFP-immunoreactive proteins of highest MM to discrete species with lower MM (Pga59GFP, $68 \mathrm{kDa}$; Pga62-GFP, $125 \mathrm{kDa}$ ), indicating that both proteins were $N$-glycosylated and subject to outer chain addition. Nevertheless, the MM of the EndoH-treated Pga59-GFP and Pga62-GFP proteins remained higher than predicted from their amino acid sequence (Pga59-GFP, $34.4 \mathrm{kDa}$; Pga62-GFP, $44.6 \mathrm{kDa}$ ), suggesting that both were also heavily $O$-glycosylated. Cell wall fractions of strains CEC56 and CEC65 were trypsinized and analysed by mass spectrometry. Abundant peptides corresponding to GFP tryptic products were detected by MALDI-TOF analysis (data not shown). LC/MS/MS analysis of cell wall fractions confirmed the identification of GFP peptides among peptides of common cell wall proteins such as Crh11, Ecm33, Ssr1, Rbt5, Ywp1, Pir1 and Rhd3/Pga29, confirming the association of Pga59-GFP and Pga62-GFP with $C$. albicans cell walls. Taken together, these data indicated that the Pga59-GFP and Pga62-GFP fusion proteins were $\mathrm{N}$ - and $\mathrm{O}$-glycosylated cell wall proteins, suggesting that the same was true for Pga59 and Pga62. The absence of tryptic peptides for Pga59 and Pga62 from trypsinized cell wall extracts of CEC56 and CEC65 might have resulted from their hyperglycosylation. Indeed, deglycosylation of cell wall extracts has enabled the identification of Pga62 by mass spectrometry (Castillo et al., 2008).

GFP-immunoreactive proteins were also found in the plasma membrane and intracellular fractions of strains 
A

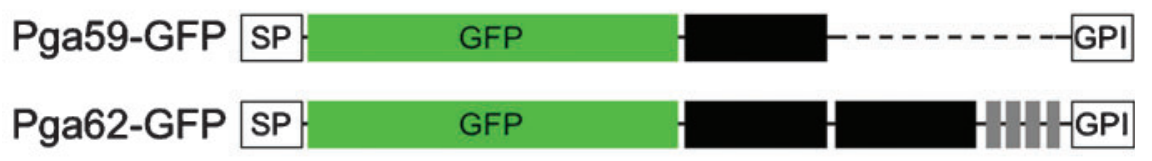

B
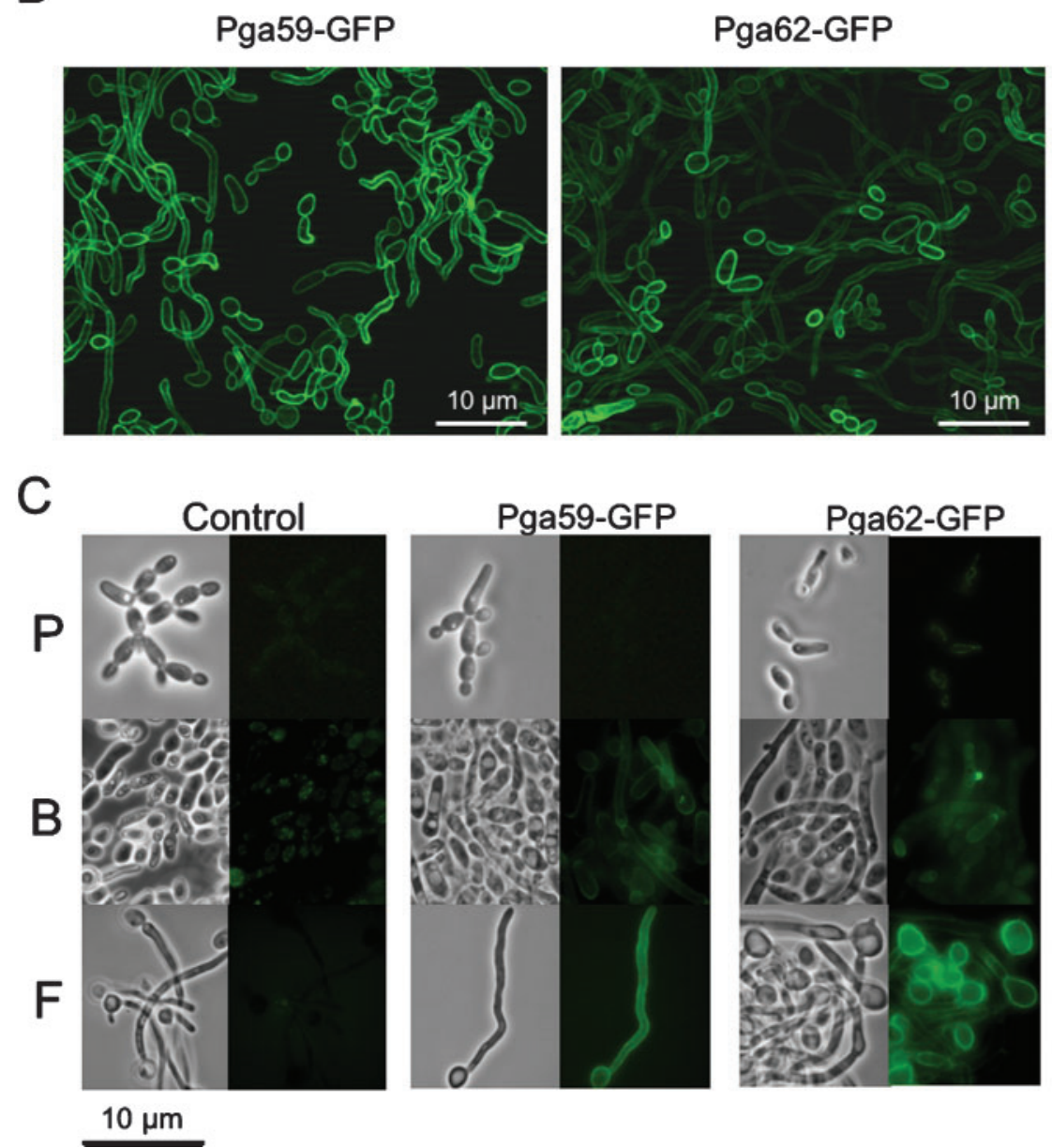

Fig. 2. The Pga59-GFP and Pga62-GFP fusion proteins are located at the cell surface of biofilm and hyphal cells. (A) Schematic representation of the Pga59-GFP and Pga62-GFP fusion proteins. The signal peptide (SP) and GPI-addition signal (GPI) downstream of the $\omega$ sites for GPI anchoring are shown as white boxes. GFP was inserted between amino acids 2 and 3 of the mature Pga59 and Pga62 proteins and is shown as a green box. The 42 aa repeats shared by Pga59 and Pga62 are shown as black boxes. The 10 aa repeats specific to Pga62 are shown as grey boxes. (B) Confocal microscopy of C. albicans strains CEC56 and CEC65 expressing the Pga59-GFP and Pga62-GFP fusion proteins, respectively. Cells were cultivated under hyphal inducing conditions (Lee's medium) and visualized using an ApoTome microscope. Fluorescence is restricted to the surface of the cells and to the septa of filamentous cells, indicative of an association of the fusion proteins with the plasma membrane or cell wall. (C) Cells of C. albicans strains BWP17 (control), CEC56 (PGa59-GFP) and CEC65 (Pga62-GFP) were grown for $24 \mathrm{~h}$ in minimal medium at $30{ }^{\circ} \mathrm{C}$ ( $\mathrm{P}$, planktonic growth), for $24 \mathrm{~h}$ on Thermanox under a continuous flow of minimal medium at $37{ }^{\circ} \mathrm{C}$ (B, biofilm) or for $2 \mathrm{~h}$ in YPD $+10 \%$ bovine serum at $37{ }^{\circ} \mathrm{C}$ (F, filamentous growth). Phase-contrast and fluorescence images of the same fields are shown.

CEC56 and CEC65, although in lesser amounts than in the cell wall fraction (Fig. 3). The MMs of these GFPimmunoreactive proteins were consistently lower than those found in the cell wall but higher than that predicted from the amino acid sequence, suggesting that they were post-translationally modified and might correspond to Pga59-GFP and Pga62-GFP proteins en route to the cell wall through the secretory pathway. 

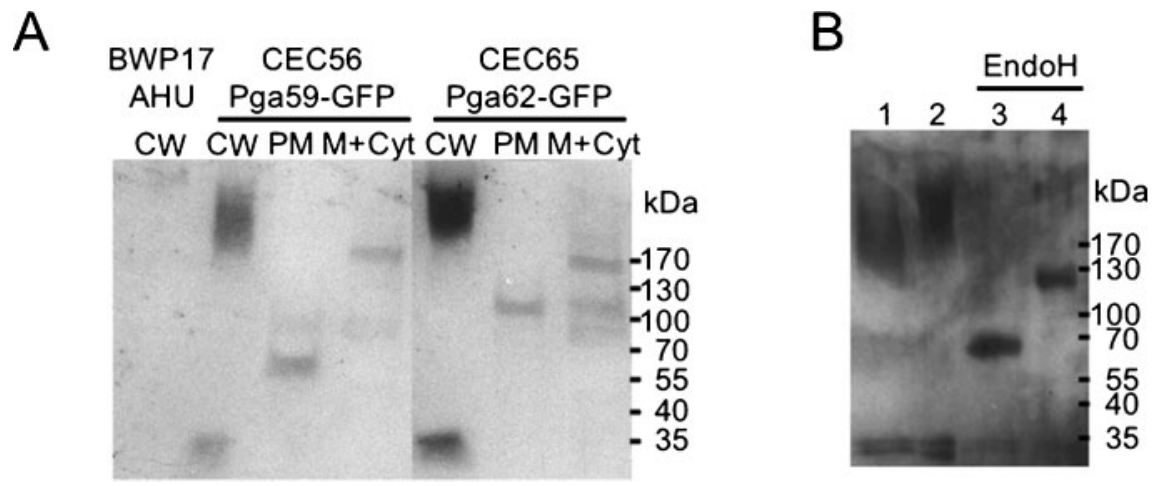

Fig. 3. The Pga59-GFP and Pga62-GFP fusion proteins are $\mathrm{N}$ - and $\mathrm{O}$-glycosylated proteins associated with the cell wall. (A) Detection of the Pga59-GFP and Pga62-GFP proteins in cell-wall-released (CW), plasma-membrane-enriched (PM), and intracellular (M+Cyt) fractions of YPD-grown C. albicans strains BWP17AHU, CEC56 and CEC65. The different fractions were separated by SDS-PAGE, transferred to nitrocellulose and GFP-immunoreactive proteins were detected using anti-GFP antibodies. (B) Detection of the Pga59-GFP (lanes 1 and 3) and Pga62-GFP (lanes 2 and 4) proteins in EndoH-untreated (lanes 1 and 2) and -treated (lanes 3 and 4) cell-wall-enriched fractions of YPD-grown C. albicans strains CEC56 and CEC65. Treated and untreated samples were fractionated by SDS-PAGE, transferred to nitrocellulose and GFP-immunoreactive proteins were detected using anti-GFP antibodies. In both panels, molecular mass markers are shown in kDa.

\section{Roles of the PGA59 and PGA62 genes in growth, filamentation and biofilm formation}

In order to investigate the role of PGA59 and PGA62, knockout mutants were constructed in the BWP17U (Table 1) background through replacement of the two alleles of PGA59 or PGA62 by the HIS1 and ARG4 genes (Gola et al., 2003), yielding strains CEC373 (pga59L/pga594) and

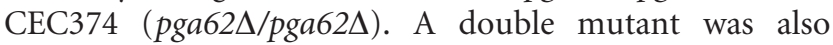
constructed, where the whole genomic region harbouring PGA59 and PGA62 was deleted. C. albicans strain CEC377

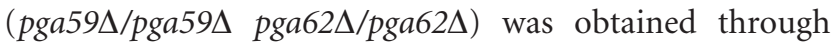
sequential replacement of the $9040 \mathrm{bp}$ region extending from the stop codon of PGA59 to the stop codon of PGA62 by the HIS1 and ARG4 genes in BWP17 (Table 1), and then by integration at the RPS10 locus of the URA3 gene carried by the CIp10 plasmid (Murad et al., 2000).
Data in Table 3 show relative fitness values (St Onge et al., 2007) for the different strains when grown in rich (YPD), minimal (SD) medium, and minimal medium supplemented with Arg, His and Uri (SD + AHU). Most mutant strains showed a modest reduction in fitness in comparison to the BWP17AHU wild-type strain. Noticeably, the pga594/pga594 mutant showed a significant decrease in fitness upon growth in SD. This growth defect was alleviated by supplementation of the SD medium with Arg, His and Uri, suggesting a poor expression of the auxotrophic markers in this mutant strain. The observation that a heterozygous PGA59/pga59D strain also showed a significant fitness reduction in SD medium (Table 3) and that reintroduction of the PGA59 gene in a pga59L/pga59 strain did not restore wild-type growth in SD medium (data not shown) was consistent with this hypothesis. The

Table 3. Relative fitness of pga59 and pga62 deletion strains

\begin{tabular}{|c|c|c|c|c|c|}
\hline \multirow[t]{2}{*}{ Strain } & \multirow[t]{2}{*}{ Genotype } & \multirow[t]{2}{*}{ Parent } & \multicolumn{3}{|c|}{ Relative fitness $(W)^{\star}$} \\
\hline & & & YPD & SD & $\mathrm{SD}+\mathrm{AHU}$ \\
\hline SC5314 & Wild-type & - & $1.14 \pm 0.02$ & $1.07 \pm 0.13$ & $1.04 \pm 0.15$ \\
\hline BWP17AHU & Wild-type & BWP17U & $1.00 \pm 0.00$ & $1.00 \pm 0.00$ & $1.00 \pm 0.00$ \\
\hline CEC373 & 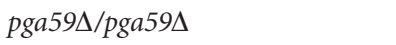 & BWP17U & $0.89 \pm 0.06$ & $0.45 \pm 0.00$ & $0.68 \pm 0.00$ \\
\hline CEC374 & 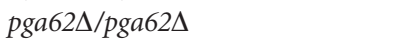 & BWP17U & $0.91 \pm 0.06$ & $0.89 \pm 0.07$ & $0.92 \pm 0.03$ \\
\hline CEC922 & PGA59/pga59s & BWP17 & $0.79 \pm 0.07$ & $0.57 \pm 0.13$ & $0.78 \pm 0.07$ \\
\hline CEC377 & 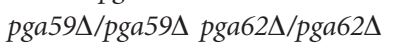 & BWP17 & $0.81 \pm 0.01$ & $0.94 \pm 0.06$ & $0.79 \pm 0.05$ \\
\hline
\end{tabular}

${ }^{\star}$ The relative fitness of a strain was defined by its specific growth rate relative to that of the wild-type BWP17AHU (St Onge et al., 2007). Fitness values are means of those obtained for at least two biological replicates, each including at least four technical replicates. 


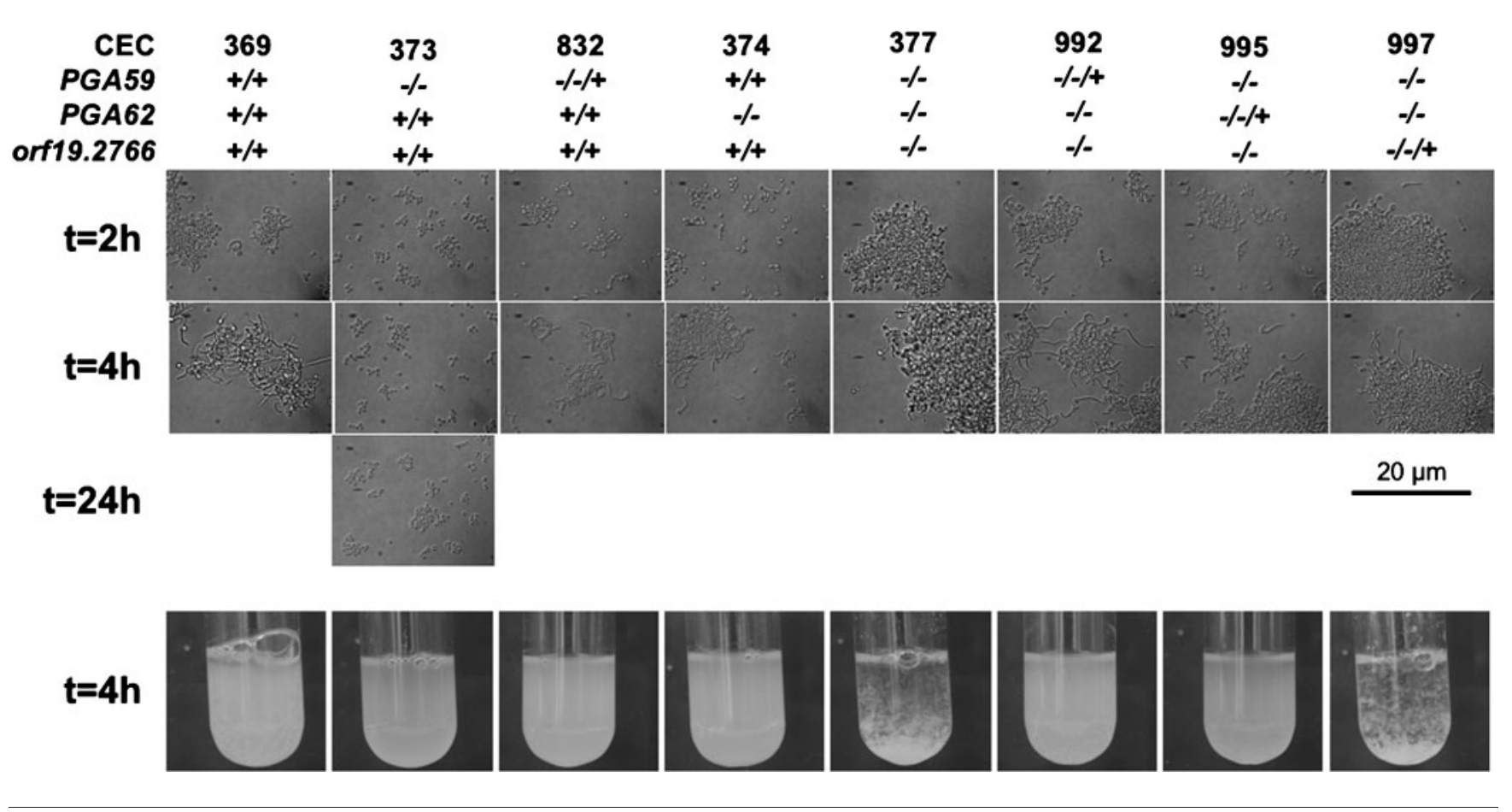

Fig. 4. Inactivation of $C$. albicans $P G A 59$ and/or $P G A 62$ results in a filamentation defect and in flocculation. Cells from $40 \mathrm{~h}$ cultures in YPD medium at $30{ }^{\circ} \mathrm{C}$ of strains CEC369, СЕС373, CEC832, CEC374, CEC377, CEC992, CEC995 and CEC997 were induced to undergo the yeast-to-hypha transition in Lee's medium. Microscopic images (upper panels) and images of cell solutions in reagent tubes (lower panel) are shown. The status of the PGA59, PGA62 and orf19.2766 genes in each strain is indicated $(+/+$, homozygous wild-type ; $-/-$, homozygous null $;-/-/+$, reconstituted).

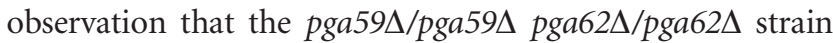
did not show such a growth defect might be due to a different configuration of the auxotrophic markers in this strain, where the whole 9040 bp PGA59-PGA62 has been deleted.

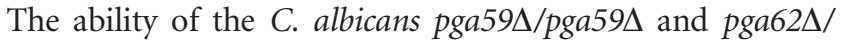
pga62 $\Delta$ mutant strains to undergo the yeast-to-hypha transition and to form biofilms was tested. Data shown in Fig. 4 indicated that inactivation of PGA59 was associated with a severe impairment of filamentation in liquid Lee's medium. A similar, although less pronounced, filamentation

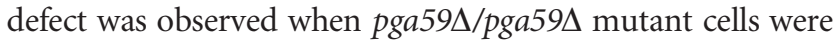
exposed to liquid RPMI medium (data not shown). Filamentation was restored upon reintroduction of the PGA59 gene, indicating that the filamentation defect in Lee's medium of the C. albicans pga59 $/ p g a 59 \Delta$ strain was a direct consequence of PGA59 inactivation (Fig. 4, upper panels). Inactivation of PGA62 slightly delayed hyphal emergence and elongation in Lee's medium (Fig. 4, upper panels). However, reintroduction of $P G A 62$ did not restore wild-type filamentation to the pga62 $/$ pga62 $\Delta$ mutant (data not shown). No significant impairment of filamentation was observed when

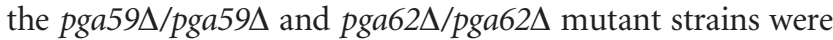
grown on solid inducing media or under embedded conditions (data not shown). Moreover, we did not observe any reproducible difference when the mutant strains were tested for their ability to form biofilms in two models of biofilm formation. These data suggested that PGA59 is necessary for morphogenesis in some conditions and that PGA59 and PGA62 are not necessary for biofilm formation despite their elevated expression upon biofilm growth.

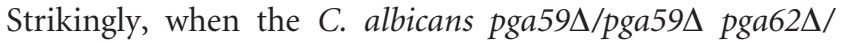
pga62 $\Delta$ double mutant was incubated in Lee's medium at $37^{\circ} \mathrm{C}$, we observed intense flocculation of germinating cells (Fig. 4, lower panels). Flocculation was reduced upon reintroduction of PGA59 or PGA62 in the double mutant while filamentation was still observed. In contrast, reintroduction of orf19.2766 did not reduce flocculation, suggesting that the flocculation phenotype was a consequence of the simultaneous inactivation of PGA59 and PGA62 but not of orf19.2766. The observation that the

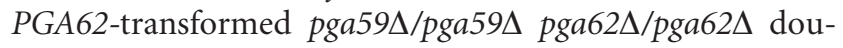
ble mutant was able to undergo hyphal morphogenesis in Lee's medium, in contrast to the pga594/pga59 single mutant, could reflect a difference in fitness in a poor medium such as Lee's medium of the pga59L/pga59 $\Delta$ and

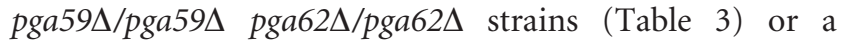
bypass of the PGA59 requirement for filamentation due to cell-to-cell contact resulting from the simultaneous inactivation of PGA59 and PGA62 (see Discussion).

\section{The PGA59 and PGA62 genes are necessary for cell wall integrity}

Because Pga59 and Pga62 were shown to be constituents of the cell wall, they could play a role in the architecture and 


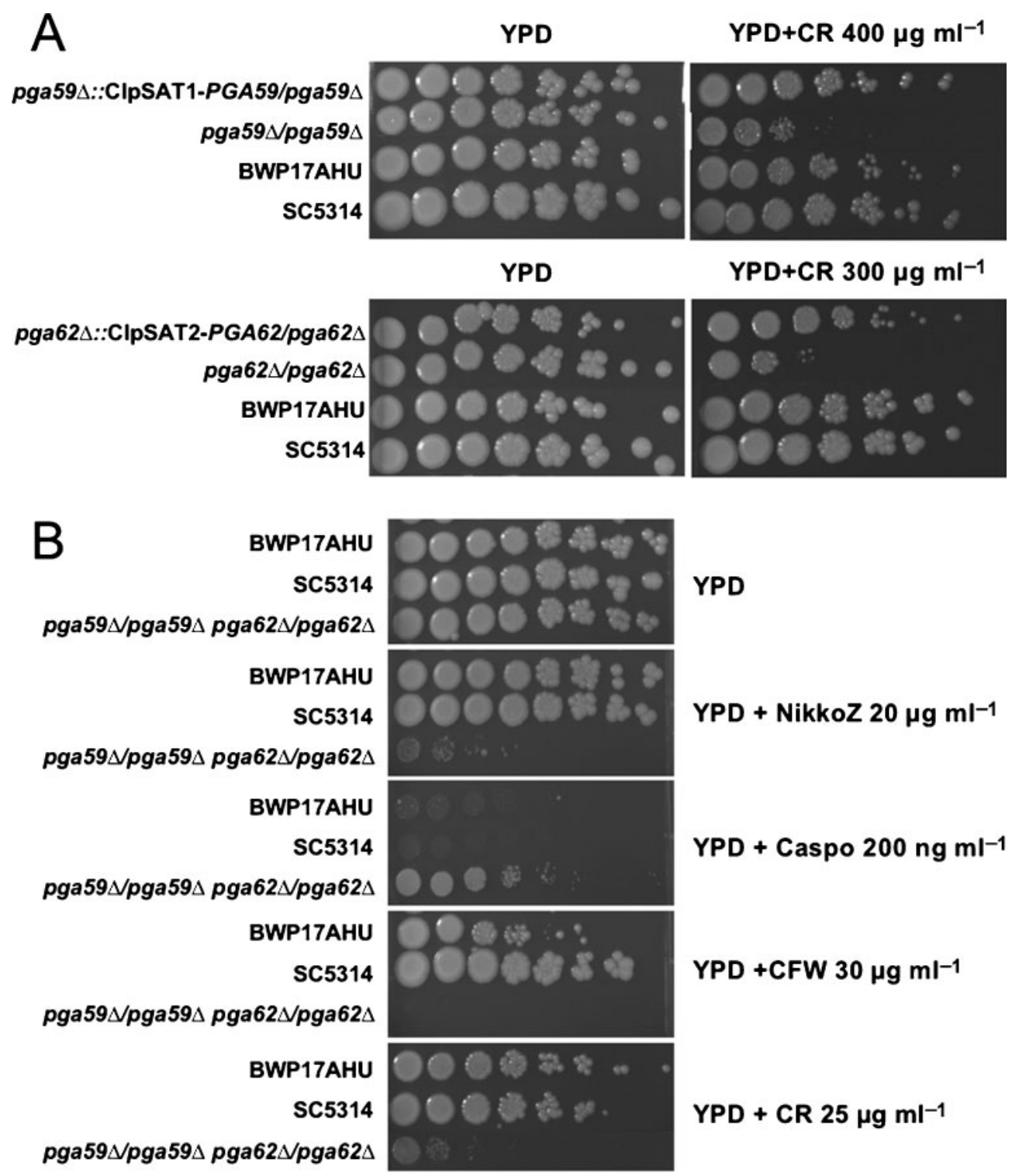

Fig. 5. Inactivation of $C$. albicans $P G A 59$ and/or $P G A 62$ results in altered sensitivity to cell-wall-perturbing agents. Overnight

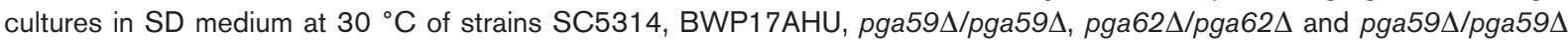

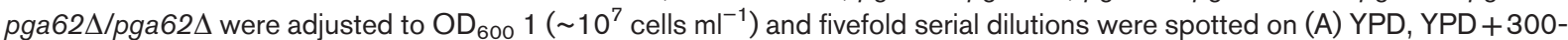
$400 \mu \mathrm{g} \mathrm{ml}^{-1}$ Congo red and (b) YPD and YPD + drugs (NikkoZ, nikkomycin Z; Caspo, caspofungin; CFW, Calcofluor white; $\mathrm{CR}$, Congo red) at the indicated concentrations. Photographs were taken after 3 days at $30{ }^{\circ} \mathrm{C}$.

integrity of the $C$. albicans cell wall. Thus, sensitivity of the $C$.

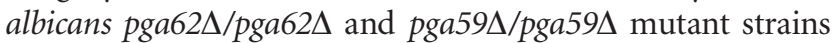
to various cell-wall-perturbing agents was tested in rich medium. Congo red (CR), Calcofluor white (CFW), nikkomycin $\mathrm{Z}$ (a chitin synthase inhibitor), and caspofungin (a $\beta-1,3$ glucan synthase inhibitor) sensitivity tests were performed on solid YPD, while sensitivity to Zymolyase ( $\beta$ 1,3 glucanase and $\beta$-1,3-glucan laminaripentao-hydrolase) and Quantazyme ( $\beta$-1,3-glucanase) was tested on cells grown in liquid YPD. As shown in Fig. 5(A), both the pga59L/

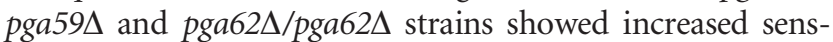
itivity to $\mathrm{CR}$ at concentrations above $300 \mu \mathrm{g} \mathrm{m}{ }^{-1}$. No difference in sensitivity to CFW, nikkomycin Z, caspofungin, Zymolyase or Quantazyme was observed for the pga62 $\Delta$ /

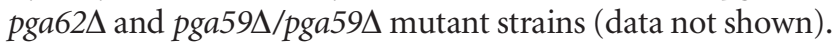

The most striking effect was observed upon deletion of both PGA59 and PGA62. As shown in Fig. 5(B), C. albicans

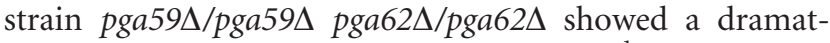
ically increased sensitivity to CR $\left(25 \mu \mathrm{g} \mathrm{ml}^{-1}\right)$, nikkomycin $\mathrm{Z}\left(20 \mu \mathrm{g} \mathrm{ml}^{-1}\right)$ and CFW $\left(30 \mu \mathrm{g} \mathrm{ml}^{-1}\right)$ and resistance to caspofungin $\left(200 \mathrm{ng} \mathrm{ml}^{-1}\right)$.

Reintroduction of the PGA59 or PGA62 genes at the cognate loci restored the original phenotype (Fig. $5 \mathrm{~A}$ ). In the case of 
Table 4. Cell wall composition of SD-grown cells of the pga59 and pga62 deletion strains

\begin{tabular}{|c|c|c|c|c|c|c|}
\hline \multirow[t]{2}{*}{ Strain } & \multirow[t]{2}{*}{ Genotype } & \multirow{2}{*}{$\begin{array}{l}\text { Chitin content } \\
\text { (\% cell wall) }\end{array}$} & \multirow{2}{*}{$\begin{array}{l}\text { Protein content } \\
\text { (\% cell wall) }\end{array}$} & \multicolumn{2}{|c|}{ Sugar content (\% cell wall) } & \multirow{2}{*}{$\begin{array}{c}\text { Ratio glucose : } \\
\text { mannose }\end{array}$} \\
\hline & & & & Glucose & Mannose & \\
\hline CEC373 & 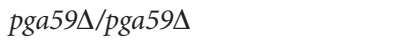 & $5.6 \pm 0.61$ & $3.4 \pm 0.0$ & $64.3 \pm 4.3$ & $20.8 \pm 2.0$ & $3.1 \pm 0.3$ \\
\hline CEC374 & 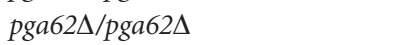 & $5.4 \pm 0.7$ & $3.3 \pm 0.1$ & $68.6 \pm 6.4$ & $23.6 \pm 2.5$ & $2.9 \pm 0.1$ \\
\hline
\end{tabular}

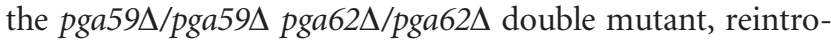
duction of either PGA59 or PGA62 gene at the RPS1 locus partly alleviated the sensitivity to CR (data not shown).

Altered sensitivity to cell-wall-perturbing agents suggested that inactivation of PGA59 and/or PGA62 might result in alterations of the cell wall composition, especially in the case

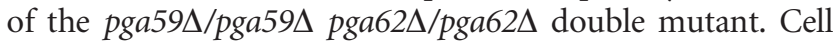
walls were isolated from SD-grown cells of strains BWP17AHU, CEC373, CEC374 and CEC377, and protein, chitin, mannan (measured as mannose) and glucan (measured as glucose) contents were measured as detailed in Methods. Results are presented in Table 4. No differences in protein content were observed. Inactivation of PGA59 and/or $P G A 62$ resulted in a 1.3 - to 1.5 -fold increase in chitin content. No significant variation in glucan and mannan levels nor in glucan: mannan ratio were observed for the

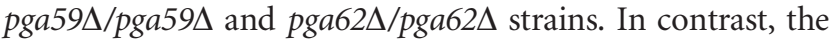

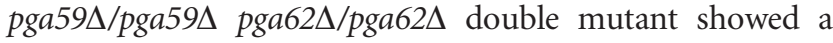
twofold reduction in the relative level of mannose and a concomitant slightly increased level of glucose (1.11). These changes were reflected in the glucose: mannose ratio, which was twice that of the control strain (Table 4). The cell wall of the different mutants was analysed by LC/MS/MS and showed a very similar cell wall proteome to that of the wildtype, with no obvious complementary changes such as the incorporation of uncommon cell wall proteins (data not shown).

In order to get further insights into potential cell wall defects

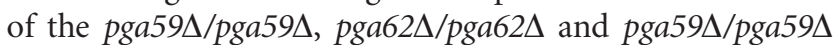
pga62 $\Delta / p g a 62 \Delta$ strains, they were grown in supplemented minimal medium and observed by electron microscopy following cryofixation. Results presented in Fig. 6 indicated significant differences between the cell wall of the mutant and wild-type strains: the inner layer of the cell wall, composed of chitin and $\beta$-1,3-glucan, was less electron-dense while the outer layer, enriched with mannoproteins, appeared disorganized in the three mutants.

Taken together, these data indicated that the cell wall Pga59 and Pga62 proteins are necessary for cell wall integrity in C. albicans.

\section{DISCUSSION}

In this study, we have investigated the contribution of the C. albicans Pga59 and Pga62 GPI-modified cell wall
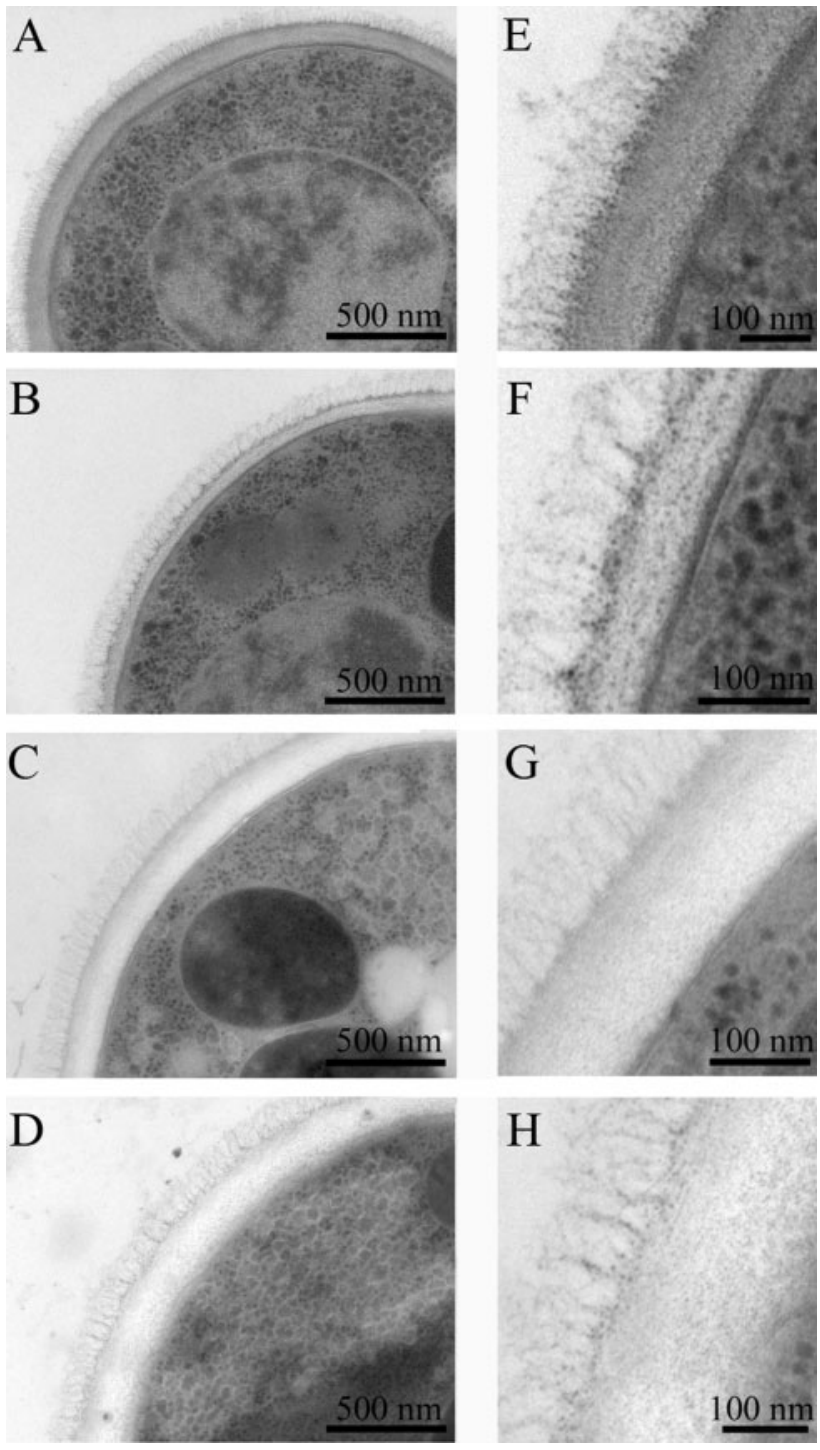

Fig. 6. Inactivation of C. albicans PGA59 and/or PGA62 results in altered cell wall morphology. Transmission electron micrographs of C. albicans cells grown in SD medium supplemented with arginine, histidine and uridine, showing the glucan/chitin-rich inner layer and mannose-rich fibrillar outer layer of the cell wall. $(A, E)$ Wild-type BWP17AHU. (B, F) CEC373 (pga594/pga594). (C, G)

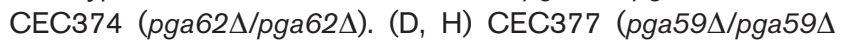

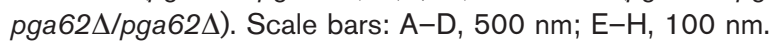


proteins to morphogenesis, biofilm formation and cell wall biogenesis. Our results show that Pga59 and, to a minor extent, Pga62, are necessary for efficient filamentation in liquid Lee's medium and liquid RPMI medium. Despite this contribution of Pga59 (and Pga62) to morphogenesis, the known link between morphogenesis and biofilm formation (Ramage et al., 2002; Richard et al., 2005) and the elevated expression of the PGA59 and PGA62 genes in C. albicans biofilms (Garcia-Sanchez et al., 2004), neither of these two genes appears to contribute to biofilm formation. Taken together, these observations suggest a minor requirement of Pga59 and Pga62 for morphogenesis, such that it does not influence biofilm formation under the conditions we have tested.

Strikingly, we observed that simultaneous inactivation of PGA59 and PGA62 results in flocculation upon hyphainductive conditions (Fig. 4), and to some extent in the stationary phase of growth (data not shown), and overrides the filamentation defect associated with the inactivation of PGA59 alone. The observation that the pga59L/pga59L mutant was defective for filamentation in Lee's medium

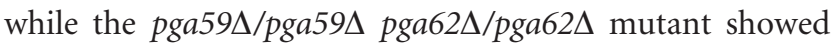
relatively unaltered filamentation might reflect differences in fitness between these two strains when grown in media that are not supplemented with uracil, arginine and histidine such as Lee's medium (Table 3). Thus, the

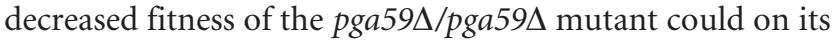
own explain the filamentation defect in Lee's medium. However, we favour an alternative hypothesis whereby flocculation resulting from the simultaneous inactivation of PGA59 and PGA62 could bypass the requirement for PGA59 for morphogenesis in Lee's medium. This hypothesis is supported by the observation that the pga59L/ pga59d mutant is not defective for contact-induced morphogenesis upon embedded growth or on surfaces. Consistent with this hypothesis, several $C$. albicans mutants (e.g. those in the SFL1, CHK1 and CRK1 genes) show flocculation and reduced thresholds for hyphal induction (Bauer \& Wendland, 2007; Calera \& Calderone, 1999; Li et al., 2007; Wang et al., 1999). However, it has not been precisely evaluated whether in these mutants the increased ability to form hyphae triggers flocculation or vice versa.

C. albicans GPI-modified cell wall proteins have been recently classified into the following groups, depending on their functions: cell wall biogenesis and remodelling, oxidant adaptation, adherence, or specific enzymic functions (Richard \& Plaine, 2007). Transcript profiling data suggested that Pga59 and Pga62 might play a role in cell wall stability, as both PGA59 and PGA62 are upregulated during protoplast regeneration (Castillo et al., 2006). Characterization of a pga62 $/$ pga62 $\Delta$ mutant in the framework of a global survey of the function of GPImodified proteins in C. albicans has suggested that Pga62 indeed plays a role in cell wall stability, as inactivation of PGA62 was associated with Calcofluor white sensitivity, resistance to caspofungin, and an increase in cell wall chitin content and thickness (Plaine et al., 2008). Data presented in this study confirm the involvement of Pga62 in $C$. albicans cell wall stability and extend this involvement to Pga59. In particular, we have shown that inactivation of PGA59 and/or PGA62 is associated with (i) increased levels of chitin in the cell wall, (ii) a cell wall inner layer with decreased electron density and (iii) disorganization of the cell wall outer layer. An increase in chitin levels is known in yeasts to compensate for alterations in the cell wall (Kapteyn et al., 2000; Popolo et al., 2001; Richard et al., 2002a; Walker et al., 2008) and to correlate with increased sensitivity to Congo red, a cell wall binding dye known to interfere with the proper assembly of cell wall components (Herth, 1980; Imai et al., 2005). Consistently, the pga59L/

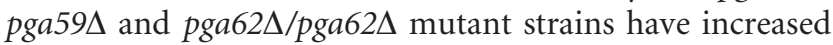
sensitivity to Congo red. This effect is exacerbated in the

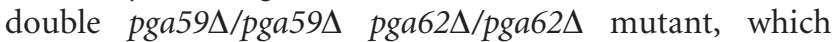
becomes highly sensitive to Congo red, Calcofluor white, a fluorescent stain that binds to nascent chitin molecules and, conceivably, also interferes with the attachment of chitin to $\beta$-1,3-glucan (Herth, 1980), and nikkomycinZ, a competitive inhibitor of chitin synthases (Cabib, 1991). These results suggest that chitin biosynthesis is essential to circumvent deleterious effects on the cell wall of mutations in the PGA59 and PGA62 genes. Consistent with increased chitin levels and changes in the cell wall is the resistance of

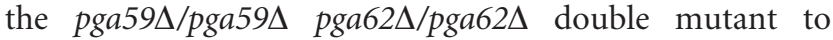
caspofungin. The echinocandin caspofungin is an inhibitor of the Fks1 glucan synthase, thus interfering with the polymerization of UDP-glucose into the cell wall polymer $\beta$-1,3-glucan and in the late stages of $\beta-1,6$-glucan synthesis (Kurtz \& Douglas, 1997; Stevens et al., 2006). Compensatory upregulation of chitin synthesis is known to protect $C$. albicans cells against caspofungin in a process that involves the protein kinase C-dependent cell wall integrity pathway, the HOG MAP kinase pathway and the $\mathrm{Ca}^{2+}$-calcineurin signalling pathway (Stevens et al., 2004, 2006; Walker et al., 2008; Wiederhold et al., 2005). However, the exact nature of the cell wall modification that triggers increased chitin synthesis in the single and

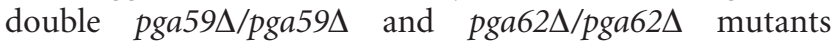
remains unclear. Analysis of the cell wall did not indicate any deficiency in glucan synthesis, as only the pga59 $/$

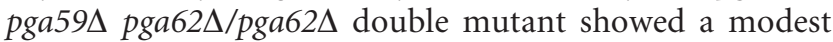
increase in cell wall glucans that may contribute to further compensation of cell wall defects due to the simultaneous inactivation of PGA59 and PGA62. The pga59L/pga59A

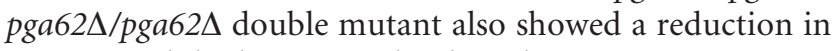
mannose while the protein levels and protein composition of the wall remained unaltered. This may reflect an alteration in the level of mannosylation of the mannoproteins found in the outer layer of the cell wall, consistent with the disorganization of this cell wall layer observed upon electron microscopy. It may also reflect the absence of the abundant, highly mannosylated Pga59 and Pga62 proteins from the cell wall. That no obvious difference was seen between the single and double mutants might be due to the inherent limitations of our ultrastructural analysis. 
What then could be the function of Pga59 and Pga62 in the cell wall? The cell-wall-bound mature Pga59 and Pga62 proteins are essentially constituted of one or two repeats of a 42 aa domain that is shared by several other $C$. albicans cell wall proteins as well as cell wall proteins in other yeast species (e.g. the S. cerevisiae Ccw12 protein, also a short and presumably abundant GPI-cell wall protein as indicated by a high codon adaptation index; Christie et al., 2004; Ragni et al., 2007). Heterologous expression of derivatives of the $C$. albicans Eap1 protein in S. cerevisiae suggests that a larger repeated domain encompassing the 42 aa domain is involved in cellular aggregation (Li \& Palecek, 2008). Interestingly, the 42 aa domain harbours three conserved cysteine residues along with aromatic residues, serine and threonine residues and hydrophobic residues. It is therefore reminiscent of domains that have been shown to bind cell wall polymers (Boraston et al., 2004) such as those found in the Gas1 family of transglucosidases (Popolo et al., 2008) or Eng1 family of endoglucanases (Martín-Cuadrado et al., 2008). Therefore, the repeated domains in Pga59 and Pga62 might be involved in interacting with cell wall polysaccharides and consequently reinforce the integrity of the cell wall. Alternatively, conserved cysteine residues in the 42-residue repeats might be involved in intermolecular disulfide bridges that could also reinforce the integrity of the cell wall. It has been shown that treatment of yeasts with reducing agents increases the porosity of the cell wall, suggesting that disulfide bridges might contribute to cell wall organization (De Nobel et al., 1990a, b). The 42-residue-repeat-containing cell wall-bound proteins might be responsible for cell wall stability dependent on disulfide bridges, some proteins such as Pga59 and Pga62 performing only this function while proteins such as the Cht 2 chitinase and the Hwp1 and Eap1 adhesins perform additional functions. In this regard, a structural role of Pga59 and Pga62 in the cell wall is supported by their probable abundance, as suggested by a high codon adaptation index (0.75; Sharp \& Li, 1987; Wu et al., 2005), and an even distribution in the cell wall of yeast, pseudohyphal and hyphal cells. Detailed studies on the role of the cysteine residues in Pga59 or Pga62 function should help test this hypothesis.

\section{ACKNOWLEDGEMENTS}

We thank all past and present members of the d'Enfert group, Marinela Budroni and Quirico Migheli for support and helpful hints during the long course of this study. We are grateful to Emmanuelle Perret and Pascal Roux for help with confocal microscopy and to Henk Dekker and Qing Yuan Yin (UvA-SILS) for assistance with mass spectrometry. Caspofungin was kindly provided by Merck \& Co., Inc. This work was supported by the European Union (MRTN-CT-2003-504148 Galar Fungail II). G. O. was the recipient of a grant of the Italian Ministry of Agriculture, Project 'FRU.MED', Subproject 'DAFME'.

\section{REFERENCES}

Albrecht, A., Felk, A., Pichova, I., Naglik, J. R., Schaller, M., de Groot, P., Maccallum, D., Odds, F. C., Schafer, W. \& other authors (2006).
Glycosylphosphatidylinositol-anchored proteases of Candida albicans target proteins necessary for both cellular processes and hostpathogen interactions. J Biol Chem 281, 688-694.

Bates, S., de la Rosa, J. M., MacCallum, D. M., Brown, A. J., Gow, N. A. \& Odds, F. C. (2007). Candida albicans Iff11, a secreted protein required for cell wall structure and virulence. Infect Immun 75, 29222928.

Bauer, J. \& Wendland, J. (2007). Candida albicans Sfll suppresses flocculation and filamentation. Eukaryot Cell 6, 1736-1744.

Boraston, A. B., Bolam, D. N., Gilbert, H. J. \& Davies, G. J. (2004). Carbohydrate-binding modules: fine-tuning polysaccharide recognition. Biochem J 382, 769-781.

Braun, B. R., Head, W. S., Wang, M. X. \& Johnson, A. D. (2000). Identification and characterization of TUP1-regulated genes in Candida albicans. Genetics 156, 31-44.

Braun, B. R., van Het Hoog, M., d'Enfert, C., Martchenko, M., Dungan, J., Kuo, A., Inglis, D. O., Uhl, M. A., Hogues, H. \& other authors (2005). A human-curated annotation of the Candida albicans genome. PLoS Genet 1, e1. doi:10.1371/journal.pgen.0010001.

Cabib, E. (1991). Differential inhibition of chitin synthetases 1 and 2 from Saccharomyces cerevisiae by polyoxin D and nikkomycins. Antimicrob Agents Chemother 35, 170-173.

Calera, J. A. \& Calderone, R. (1999). Flocculation of hyphae is associated with a deletion in the putative CaHK1 two-component histidine kinase gene from Candida albicans. Microbiology 145, 14311442.

Cantero, P. D., Lengsfeld, C., Prill, S. K., Subanovic, M., Roman, E., Pla, J. \& Ernst, J. F. (2007). Transcriptional and physiological adaptation to defective protein-O-mannosylation in Candida albicans. Mol Microbiol 64, 1115-1128.

Caro, L. H., Tettelin, H., Vossen, J. H., Ram, A. F., van den Ende, H. \& Klis, F. M. (1997). In silicio identification of glycosyl-phosphatidylinositol-anchored plasma-membrane and cell wall proteins of Saccharomyces cerevisiae. Yeast 13, 1477-1489.

Castillo, L., Martinez, A. I., Garcera, A., Garcia-Martinez, J., RuizHerrera, J., Valentin, E. \& Sentandreu, R. (2006). Genomic response programs of Candida albicans following protoplasting and regeneration. Fungal Genet Biol 43, 124-134.

Castillo, L., Calvo, E., Martinez, A. I., Ruiz-Herrera, J., Valentin, E., Lopez, J. A. \& Sentandreu, R. (2008). A study of the Candida albicans cell wall proteome. Proteomics 8, 3871-3881.

Christie, K. R., Weng, S., Balakrishnan, R., Costanzo, M. C., Dolinski, K., Dwight, S. S., Engel, S. R., Feierbach, B., Fisk, D. G. \& other authors (2004). Saccharomyces Genome Database (SGD) provides tools to identify and analyze sequences from Saccharomyces cerevisiae and related sequences from other organisms. Nucleic Acids Res 32 (Database issue), D311-D314.

Copping, V. M., Barelle, C. J., Hube, B., Gow, N. A., Brown, A. J. \& Odds, F. C. (2005). Exposure of Candida albicans to antifungal agents affects expression of $S A P 2$ and SAP9 secreted proteinase genes. $J$ Antimicrob Chemother 55, 645-654.

Dallies, N., Francois, J. \& Paquet, V. (1998). A new method for quantitative determination of polysaccharides in the yeast cell wall. Application to the cell wall defective mutants of Saccharomyces cerevisiae. Yeast 14, 1297-1306.

d'Enfert, C., Goyard, S., Rodriguez-Arnaveilhe, S., Frangeul, L., Jones, L., Tekaia, F., Bader, O., Albrecht, A., Castillo, L. \& other authors (2005). CandidaDB: a genome database for Candida albicans pathogenomics. Nucleic Acids Res 33, D353-D357.

De Groot, P. W. J., De Boer, A. D., Cunningham, J., Dekker, H. L., De Jong, L., Hellingwerf, K. J., De Koster, C. \& Klis, F. M. (2004). Proteomic analysis of Candida albicans cell walls reveals covalently 
bound carbohydrate-active enzymes and adhesins. Eukaryot Cell 3, 955-965.

De Groot, P. W. J., Ram, A. F. \& Klis, F. M. (2005). Features and functions of covalently linked proteins in fungal cell walls. Fungal Genet Biol 42, 657-675.

De Nobel, J. G., Klis, F. M., Munnik, T., Priem, J. \& van den Ende, H. (1990a). An assay of relative cell wall porosity in Saccharomyces cerevisiae, Kluyveromyces lactis and Schizosaccharomyces pombe. Yeast 6, 483-490.

De Nobel, J. G., Klis, F. M., Priem, J., Munnik, T. \& van den Ende, H. (1990b). The glucanase-soluble mannoproteins limit cell wall porosity in Saccharomyces cerevisiae. Yeast 6, 491-499.

Douglas, L. J. (2003). Candida biofilms and their role in infection. Trends Microbiol 11, 30-36.

Dujon, B., Sherman, D., Fischer, G., Durrens, P., Casaregola, S., Lafontaine, I., De Montigny, J., Marck, C., Neuveglise, C. \& other authors (2004). Genome evolution in yeasts. Nature 430, 35-44.

Dunkler, A., Walther, A., Specht, C. A. \& Wendland, J. (2005). Candida albicans CHT3 encodes the functional homolog of the Cts1 chitinase of Saccharomyces cerevisiae. Fungal Genet Biol 42, 935-947.

Enloe, B., Diamond, A. \& Mitchell, A. P. (2000). A singletransformation gene function test in diploid Candida albicans. J Bacteriol 182, 5730-5736.

Firon, A., Aubert, S., Iraqui, I., Guadagnini, S., Goyard, S., Prevost, M. C., Janbon, G. \& d'Enfert, C. (2007). The SUN41 and SUN42 genes are essential for cell separation in Candida albicans. Mol Microbiol 66, $1256-1275$

Fonzi, W. A. \& Irwin, M. Y. (1993). Isogenic strain construction and gene mapping in Candida albicans. Genetics 134, 717-728.

Frieman, M. B. \& Cormack, B. P. (2003). The omega-site sequence of glycosylphosphatidylinositol-anchored proteins in Saccharomyces cerevisiae can determine distribution between the membrane and the cell wall. Mol Microbiol 50, 883-896.

Frieman, M. B. \& Cormack, B. P. (2004). Multiple sequence signals determine the distribution of glycosylphosphatidylinositol proteins between the plasma membrane and cell wall in Saccharomyces cerevisiae. Microbiology 150, 3105-3114.

Garcia-Sanchez, S., Aubert, S., Iraqui, I., Janbon, G., Ghigo, J. M. \& d'Enfert, C. (2004). Candida albicans biofilms: a developmental state associated with specific and stable gene expression patterns. Eukaryot Cell 3, 536-545.

Garcia-Sanchez, S., Mavor, A. L., Russell, C. L., Argimon, S., Dennison, P., Enjalbert, B. \& Brown, A. J. (2005). Global roles of Ssn6 in Tup1- and Nrg1-dependent gene regulation in the fungal pathogen, Candida albicans. Mol Biol Cell 16, 2913-2925.

Gerami-Nejad, M., Berman, J. \& Gale, C. A. (2001). Cassettes for PCR-mediated construction of green, yellow, and cyan fluorescent protein fusions in Candida albicans. Yeast 18, 859-864.

Gillum, A. M., Tsay, E. Y. \& Kirsch, D. R. (1984). Isolation of the Candida albicans gene for orotidine- $5^{\prime}$-phosphate decarboxylase by complementation of S. cerevisiae ura3 and E. coli pyrF mutations. Mol Gen Genet 198, 179-182.

Goffeau, A. \& Dufour, J. P. (1988). Plasma membrane ATPase from the yeast Saccharomyces cerevisiae. Methods Enzymol 157, 528-533.

Gola, S., Martin, R., Walther, A., Dunkler, A. \& Wendland, J. (2003). New modules for PCR-based gene targeting in Candida albicans: rapid and efficient gene targeting using $100 \mathrm{bp}$ of flanking homology region. Yeast 20, 1339-1347.

Goyard, S., Knechtle, P., Chauvel, M., Mallet, A., Prevost, M. C., Proux, C., Coppee, J. Y., Schwartz, P., Dromer, F. \& other authors
(2008). The Yak1 kinase is involved in the initiation and maintenance of hyphal growth in Candida albicans. Mol Biol Cell 19, 2251-2266.

Granger, B. L., Flenniken, M. L., Davis, D. A., Mitchell, A. P. \& Cutler, J. E. (2005). Yeast wall protein 1 of Candida albicans. Microbiology 151, 1631-1644.

Hamada, K., Terashima, H., Arisawa, M., Yabuki, N. \& Kitada, K. (1999). Amino acid residues in the omega-minus region participate in cellular localization of yeast glycosylphosphatidylinositol-attached proteins. J Bacteriol 181, 3886-3889.

Harcus, D., Nantel, A., Marcil, A., Rigby, T. \& Whiteway, M. (2004). Transcription profiling of cyclic AMP signaling in Candida albicans. Mol Biol Cell 15, 4490-4499.

Herth, W. (1980). Calcofluor white and Congo red inhibit chitin microfibril assembly of Poterioochromonas: evidence for a gap between polymerization and microfibril formation. J Cell Biol 87, 442-450.

Honraet, K., Goetghebeur, E. \& Nelis, H. J. (2005). Comparison of three assays for the quantification of Candida biomass in suspension and CDC reactor grown biofilms. J Microbiol Methods 63, 287-295.

Imai, K., Noda, Y., Adachi, H. \& Yoda, K. (2005). A novel endoplasmic reticulum membrane protein Rcrl regulates chitin deposition in the cell wall of Saccharomyces cerevisiae. J Biol Chem 280, 8275-8284.

Jeffries, T. W., Grigoriev, I. V., Grimwood, J., Laplaza, J. M., Aerts, A., Salamov, A., Schmutz, J., Lindquist, E., Dehal, P. \& other authors (2007). Genome sequence of the lignocellulose-bioconverting and xylose-fermenting yeast Pichia stipitis. Nat Biotechnol 25, 319-326.

Kapteyn, J. C., Montijn, R. C., Vink, E., de la Cruz, J., Llobell, A., Douwes, J. E., Shimoi, H., Lipke, P. N. \& Klis, F. M. (1996). Retention of Saccharomyces cerevisiae cell wall proteins through a phosphodiester-linked $\beta$-1,3-/ $\beta$-1,6-glucan heteropolymer. Glycobiology 6, 337345.

Kapteyn, J. C., Hoyer, L. L., Hecht, J. E., Muller, W. H., Andel, A., Verkleij, A. J., Makarow, M., Van Den Ende, H. \& Klis, F. M. (2000). The cell wall architecture of Candida albicans wild-type cells and cell wall-defective mutants. Mol Microbiol 35, 601-611.

Kapteyn, J. C., ter Riet, B., Vink, E., Blad, S., De Nobel, H., Van Den Ende, H. \& Klis, F. M. (2001). Low external pH induces HOG1dependent changes in the organization of the Saccharomyces cerevisiae cell wall. Mol Microbiol 39, 469-479.

Klis, F. M., de Groot, P. \& Hellingwerf, K. (2001). Molecular organization of the cell wall of Candida albicans. Med Mycol 39 (Suppl 1), 1-8.

Klis, F. M., Boorsma, A. \& De Groot, P. W. (2006). Cell wall construction in Saccharomyces cerevisiae. Yeast 23, 185-202.

Kollar, R., Reinhold, B. B., Petrakova, E., Yeh, H. J., Ashwell, G., Drgonova, J., Kapteyn, J. C., Klis, F. M. \& Cabib, E. (1997). Architecture of the yeast cell wall. Beta $(1->6)$-glucan interconnects mannoprotein, $\beta(1 \rightarrow) 3$-glucan, and chitin. J Biol Chem 272, 17762-17775.

Kurtz, M. B. \& Douglas, C. M. (1997). Lipopeptide inhibitors of fungal glucan synthase. J Med Vet Mycol 35, 79-86.

Lan, C. Y., Rodarte, G., Murillo, L. A., Jones, T., Davis, R. W., Dungan, J., Newport, G. \& Agabian, N. (2004). Regulatory networks affected by iron availability in Candida albicans. Mol Microbiol 53, 1451-1469.

Latge, J. P. (2007). The cell wall: a carbohydrate armour for the fungal cell. Mol Microbiol 66, 279-290.

Lee, K. L., Buckley, H. R. \& Campbell, C. C. (1975). An amino acid liquid synthetic medium for the development of mycelial and yeast forms of Candida albicans. Sabouraudia 13, 148-153.

Lesage, G. \& Bussey, H. (2006). Cell wall assembly in Saccharomyces cerevisiae. Microbiol Mol Biol Rev 70, 317-343.

Li, F. \& Palecek, S. P. (2003). EAP1, a Candida albicans gene involved in binding human epithelial cells. Eukaryot Cell 2, 1266-1273. 
Li, F. \& Palecek, S. P. (2008). Distinct domains of the Candida albicans adhesin Eap1p mediate cell-cell and cell-substrate interactions. Microbiology 154, 1193-1203.

Li, Y., Su, C., Mao, X., Cao, F. \& Chen, J. (2007). Roles of Candida albicans Sfl1 in hyphal development. Eukaryot Cell 6, 2112-2121.

Liu, H., Kohler, J. \& Fink, G. R. (1994). Suppression of hyphal formation in Candida albicans by mutation of a STE12 homolog. Science 266, 1723-1726.

Lo, H. J., Köhler, J. R., DiDomenico, B., Loebenberg, D., Cacciapuoti, A. \& Fink, G. R. (1997). Nonfilamentous C. albicans mutants are avirulent. Cell 90, 939-949.

Mao, Y., Zhang, Z., Gast, C. \& Wong, B. (2008). C-terminal signals regulate targeting of glycosylphosphatidylinositol-anchored proteins to the cell wall or plasma membrane in Candida albicans. Eukaryot Cell 7, 1906-1915.

Martín-Cuadrado, A. B., Encinar del Dedo, J. E., de MedinaRedondo, M., Fontaine, T., del Rey, F., Latgé, J. P. \& Vázquez de Aldana, C. R. (2008). The Schizosaccharomyces pombe endo-1,3- $\beta$ glucanase Eng1 contains a novel carbohydrate binding module required for septum localization. Mol Microbiol 69, 188-200.

McCreath, K. J., Specht, C. A. \& Robbins, P. W. (1995). Molecular cloning and characterization of chitinase genes from Candida albicans. Proc Natl Acad Sci U S A 92, 2544-2548.

Murad, A. M., Lee, P. R., Broadbent, I. D., Barelle, C. J. \& Brown, A. J. (2000). CIp10, an efficient and convenient integrating vector for Candida albicans. Yeast 16, 325-327.

Netea, M. G., Gow, N. A., Munro, C. A., Bates, S., Collins, C., Ferwerda, G., Hobson, R. P., Bertram, G., Hughes, H. B. \& other authors (2006). Immune sensing of Candida albicans requires cooperative recognition of mannans and glucans by lectin and Tolllike receptors. J Clin Invest 116, 1642-1650.

Niimi, K., Harding, D. R., Parshot, R., King, A., Lun, D. J., Decottignies, A., Niimi, M., Lin, S., Cannon, R. D. \& other authors (2004). Chemosensitization of fluconazole resistance in Saccharomyces cerevisiae and pathogenic fungi by a D-octapeptide derivative. Antimicrob Agents Chemother 48, 1256-1271.

Plaine, A., Walker, L., Da Costa, G., Mora-Montes, H. M., McKinnon, A., Gow, N. A., Gaillardin, C., Munro, C. A. \& Richard, M. L. (2008). Functional analysis of Candida albicans GPI-anchored proteins: roles in cell wall integrity and caspofungin sensitivity. Fungal Genet Biol 45, 1404-1414.

Popolo, L., Gualtieri, T. \& Ragni, E. (2001). The yeast cell-wall salvage pathway. Med Mycol 39 (Suppl 1), 111-121.

Popolo, L., Ragni, E., Carotti, C., Palomares, O., Aardema, R., Back, J. W., Dekker, H. L., de Koning, L. J., de Jong, L. \& de Koster, C. G. (2008). Disulfide bond structure and domain organization of yeast $\beta(1,3)$-glucanosyltransferases involved in cell wall biogenesis. J Biol Chem 283, 18553-18565.

Ragni, E., Sipiczki, M. \& Strahl, S. (2007). Characterization of Ccw12p, a major key player in cell wall stability of Saccharomyces cerevisiae. Yeast 24, 309-319.

Ramage, G., VandeWalle, K., Lopez-Ribot, J. L. \& Wickes, B. L. (2002). The filamentation pathway controlled by the Efg1 regulator protein is required for normal biofilm formation and development in Candida albicans. FEMS Microbiol Lett 214, 95-100.

Reuss, O., Vik, A., Kolter, R. \& Morschhauser, J. (2004). The SAT1 flipper, an optimized tool for gene disruption in Candida albicans. Gene 341, 119-127.

Richard, M. L. \& Plaine, A. (2007). Comprehensive analysis of glycosylphosphatidylinositol-anchored proteins in Candida albicans. Eukaryot Cell 6, 119-133.
Richard, M., De Groot, P., Courtin, O., Poulain, D., Klis, F. \& Gaillardin, C. (2002a). GPI7 affects cell-wall protein anchorage in Saccharomyces cerevisiae and Candida albicans. Microbiology 148, 2125-2133.

Richard, M., Ibata-Ombetta, S., Dromer, F., Bordon-Pallier, F., Jouault, T. \& Gaillardin, C. (2002b). Complete glycosylphosphatidylinositol anchors are required in Candida albicans for full morphogenesis, virulence and resistance to macrophages. Mol Microbiol 44, 841-853.

Richard, M. L., Nobile, C. J., Bruno, V. M. \& Mitchell, A. P. (2005). Candida albicans biofilm-defective mutants. Eukaryot Cell 4, 1493-1502.

Rossignol, T., Lechat, P., Cuomo, C., Zeng, Q., Moszer, I. \& d'Enfert, C. (2008). CandidaDB: a multi-genome database for Candida species and related Saccharomycotina. Nucleic Acids Res 36, D557-D561.

Ruiz-Herrera, J., Elorza, M. V., Valentin, E. \& Sentandreu, R. (2006). Molecular organization of the cell wall of Candida albicans and its relation to pathogenicity. FEMS Yeast Res 6, 14-29.

Saville, S. P., Lazzell, A. L., Monteagudo, C. \& Lopez-Ribot, J. L. (2003). Engineered control of cell morphology in vivo reveals distinct roles for yeast and filamentous forms of Candida albicans during infection. Eukaryot Cell 2, 1053-1060.

Sharp, P. M. \& Li, W. H. (1987). The codon Adaptation Index - a measure of directional synonymous codon usage bias, and its potential applications. Nucleic Acids Res 15, 1281-1295.

Shen, J., Guo, W. \& Köhler, J. R. (2005). CaNAT1, a heterologous dominant selectable marker for transformation of Candida albicans and other pathogenic Candida species. Infect Immun 73, 1239-1242.

Sohn, K., Urban, C., Brunner, H. \& Rupp, S. (2003). EFG1 is a major regulator of cell wall dynamics in Candida albicans as revealed by DNA microarrays. Mol Microbiol 47, 89-102.

Sosinska, G. J., de Groot, P. W., Teixeira de Mattos, M. J., Dekker, H. L., de Koster, C. G., Hellingwerf, K. J. \& Klis, F. M. (2008). Hypoxic conditions and iron restriction affect the cell-wall proteome of Candida albicans grown under vagina-simulative conditions. Microbiology 154, 510-520.

Staab, J. F. \& Sundstrom, P. (1998). Genetic organization and sequence analysis of the hypha-specific cell wall protein gene HWP1 of Candida albicans. Yeast 14, 681-686.

Stevens, D. A., Espiritu, M. \& Parmar, R. (2004). Paradoxical effect of caspofungin: reduced activity against Candida albicans at high drug concentrations. Antimicrob Agents Chemother 48, 3407-3411.

Stevens, D. A., Ichinomiya, M., Koshi, Y. \& Horiuchi, H. (2006). Escape of Candida from caspofungin inhibition at concentrations above the MIC (paradoxical effect) accomplished by increased cell wall chitin; evidence for $\beta$-1,6-glucan synthesis inhibition by caspofungin. Antimicrob Agents Chemother 50, 3160-3161.

Stoldt, V. R., Sonneborn, A., Leuker, C. E. \& Ernst, J. F. (1997). Efglp, an essential regulator of morphogenesis of the human pathogen Candida albicans, is a member of a conserved class of bHLH proteins regulating morphogenetic processes in fungi. EMBO J 16, 1982-1991.

St Onge, R. P., Mani, R., Oh, J., Proctor, M., Fung, E., Davis, R. W., Nislow, C., Roth, F. P. \& Giaever, G. (2007). Systematic pathway analysis using high-resolution fitness profiling of combinatorial gene deletions. Nat Genet 39, 199-206.

Sundstrom, P. (2002). Adhesion in Candida spp. Cell Microbiol 4, 461-469.

Thomas, J. R., Dwek, R. A. \& Rademacher, T. W. (1990). Structure, biosynthesis, and function of glycosylphosphatidylinositols. Biochemistry 29, 5413-5422.

Tiede, A., Bastisch, I., Schubert, J., Orlean, P. \& Schmidt, R. E. (1999). Biosynthesis of glycosylphosphatidylinositols in mammals and unicellular microbes. Biol Chem 380, 503-523. 
van der Vaart, J. M., van Schagen, F. S., Mooren, A. T., Chapman, J. W., Klis, F. M. \& Verrips, C. T. (1996). The retention mechanism of cell wall proteins in Saccharomyces cerevisiae. Wall-bound Cwp2p is $\beta$ 1,6-glucosylated. Biochim Biophys Acta 1291, 206-214.

Walker, L. A., Munro, C. A., de Bruijn, I., Lenardon, M. D., McKinnon, A. \& Gow, N. A. (2008). Stimulation of chitin synthesis rescues Candida albicans from echinocandins. PLoS Pathog 4, e1000040.

Walther, A. \& Wendland, J. (2003). An improved transformation protocol for the human fungal pathogen Candida albicans. Curr Genet 42, 339-343.

Wang, Q., Zhou, S. \& Chen, J. Y. (1999). Functions of CRK1 gene of Candida albicans as studied by gene knock-out. Sheng Wu Hua Xue Yu Sheng Wu Wu Li Xue Bao (Shanghai) 31, 545-552.

Wiederhold, N. P., Kontoyiannis, D. P., Prince, R. A. \& Lewis, R. E. (2005). Attenuation of the activity of caspofungin at high concentrations against Candida albicans: possible role of cell wall integrity and calcineurin pathways. Antimicrob Agents Chemother 49, 5146-5148.

Wilson, R. B., Davis, D. \& Mitchell, A. P. (1999). Rapid hypothesis testing with Candida albicans through gene disruption with short homology regions. J Bacteriol 181, 1868-1874.

Wu, G., Culley, D. E. \& Zhang, W. (2005). Predicted highly expressed genes in the genomes of Streptomyces coelicolor and Streptomyces avermitilis and the implications for their metabolism. Microbiology 151, 2175-2187.

Yin, Q. Y., de Groot, P. W., Dekker, H. L., de Jong, L., Klis, F. M. \& de Koster, C. G. (2005). Comprehensive proteomic analysis of Saccharomyces cerevisiae cell walls: identification of proteins covalently attached via glycosylphosphatidylinositol remnants or mild alkali-sensitive linkages. J Biol Chem 280, 20894-20901.

Edited by: J. F. Ernst 